THE

\title{
UNITY OF NATURE
}

\section{$11,1.111 \%$ \\ (1)I.IRI:1.

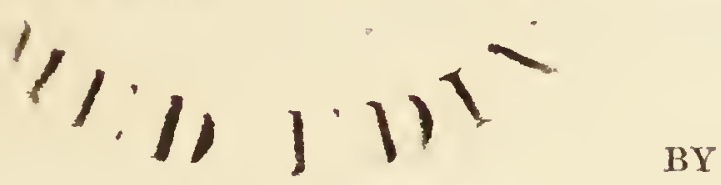

\section{CHARLES BLAND RADCLIFFE, M.B.}

LICENTIATE OF TIE ROTAL COLLFGE OF PIIYSICIANQ;

LECTURER ON VEGETABLE PIISIOLOGY AND BOTANY AT THE WESTMINETER IIOSPITAL, ETC.

"Die Geiftermelt ift nidgt veritglofien;

Dein Sinn ift zu, bein serg ift toot!

Aluf, bade, Ecljüler miseroroffen

Die irsfde Bruft im Morgenroty!"

Faust.

LONDON :

JOHN CHURCHILL, PRINCES STREET, SOHO. 
$R 55271$ 


\section{CON T EN T S.}

INTRODUC'IION

\section{CHAPTER I.}

$$
\text { OF UNITY IN FORM. }
$$

I. Of UNity in the forms of ORganic Nature . . . 8

I.

OF UNITY IN THE ORGANS OF LIVING BODIES $. \quad . \quad$. 9

1. In the plant . . . . . . . . . . . . . 9

2. In the animal . . . . . . . . . . 23

II.

OF UNITY IN THE ENTIRE ORGANISM . . . . . . 31

1. In the plant . . . . . . . . . . . 31

2. In the animal . . . . . . . . . . 34

III.

Of UNity in Plant aNd ANimal . . . . . . . 45

1. General considerations in favour of this doctrine . 46

2. Special arguments in demonstration of it . . 53

Of the primary and fundamental hindrance to the discovery of unity in organic nature-namely, the archetypal law of the vertebra, and of the partial removal of this difficulty . . . . . . . 53 
Of unity in the nervous, vaseular, osseous, and other systems, of which the animal frame is eonstituted .

PAGE

\section{2.}

Of unity in the vertebral and anellose zones

Of unity in the arehetypal law of the plant and animal

II. Of UNity IN the Foris OF ORganic AND inorganic NATURE . . . . . . . . . . . 94

1. In relation to outward shape . . . . . . 95

2. In relation to strueture . . . . . . . . . 99

3. In relation to function . . . . . . . . 101

CHAPTER II.

OF UNITY IN FORCE.

I. OF UNITY IN THE FORCE ASSOCIATED WitiI UNokGANIZED SUBSTANCES . . . . . . 107

Of the arguments by which Mr. Grove demonstrates correlation and reeiprocal dependenee in heat, light, electricity, magnetism, chemical affinity and motion-namely, in those agencies whieh constitute the foree of inorganic matter . . . . . . 107

Of a more intimate union than correlation in these ageneies . . . . . . . . . . 117

II. OF UNITY IN THE FORCE OF ORGANIC AND moRgaNiC NATURE 
1.

Of the presence in organic bodies of the force which is found in unorganized substances . . . . . 123

Of unity in the phenomena of vital force . . . . 124

1. Of the vital force in $\operatorname{man}$. . . . . . . . . 124

Of the neccssity to employ metaphysical reasonings in order to arrive at a knowledge of this force; and of the impossibility to arrive at this knowledge if the present state of man be assumed as a perfect standard of judgment . . . . . . . . . .

Of the necessity of Revelation to determine the true physical condition of man . . . . . . . .

Of the possibility to solve in part the problem of life when creation is interpreted by Revelation. Of the relation between the vitality of man and the brute, both in bodily and mental phenomena . . 137

Of absolute unity in the vital essence . . . . . 139

2. Of unity in the twofold force of living bodiesnamely, in the principle of life, and in the force associated with the matter of these bodies-as mere matte

Of correlation, or reciprocal dependence in these forces

Of unity in these forces

Of the final proofs of unity, and the possibility of showing, not only that all physical and vital forces will merge into one, but also, that the union will extend from form to force, and include mattcr and spirit. . . . . . . . . . . . . 142 
Digitized by the Internet Archive in 2016 
THE

UNITY OF NATURE. 



\section{THE UNI'Y OF NATURE.}

INTRODUCTION.

MaNY thoughtful and philosophical men have believed in the existence of a common idea or principle in the works of Nature, by which all things are linked together in one, and the joint dictates of experience and tradition are in harmony with this belief.

Since the time when Hunter gave a new impulse to the study of life, great progress has been made towards the discovery of a uniform law in the animal world; and at the present day the labours of such men as Oken, Carus, Owen, Maclise, and others, enable us to approach continually nearer to this end. Among plants there are signs of all iance and affinity on every hand, and those who, like Goethe and Linnæus, have penetrated beneath the surface, perceive an archetypal resemblance in parts which differ greatly in outward character. Newton discovered order in the perturba- 
tion of the heavens; and very recently, Faraday and Grove have taught us to expect that all agencics associated with inorganic bodies will eventually merge in a central power, of which universal gravity is but a symptom or expression. In many places, the barriers which divide the organic and inorganic worlds are broken down, and - as an earnest of the richer harvest which is to come when the separation is more completely forgotten - several phenomena which were once deemed vital and peculiar to living bodies, are now explained by ordinary physical influences. It would seem, indeed, that in every department of science there are signs which betray the presence of a universal and parent idea.

The doctrine of unity in nature belonged also to that early period when the relics of pristine wisdom still lingered upon earth, and that this was the case we may learn from the tradition which is embodied in the ancient allegory of Proteus.

This fabulous being is represented by the poets as an old man of divine parentage, who had his home in a cavern near the sea. He had the care of the herd of Neptune, and over this he presided as a keeper whose duty was to tend and provide for its increase and welfare, while in return for this service, he received from his patron the knowledge of past, present, and future, together with the oflice of interpreting mysteries to man. Each noon it was his custom to 
count his wards, and then to rest; and at this time he would exercise his oracular powers, and reply to those who were able to prevail with him. The victory, however, was extremely difficult, for the mystical herdsman would disguise himself as beast, or water, or flame, and vanish away without granting any answer, unless he were matched by a power which could compel him to return to the human form.

The principal design of this fable is to convey a knowledge of the mysteries of Nature, and to explain the relation of man to subordinate creatures and things; and this will be seen if we study it with care and patience.

The identity of Proteus with Nature is seen in the strange power of transformation which he possesses. $\mathrm{He}$ is capable of changing into any existing object, and is perfectly embodied on every occasion; and, therefore, he may be regarded as the personification of each individual part, and of the entire system of terrestrial things.

He is said to reside in a cave, in order to fix the attention upon the connexion with inanimate creation, lest in studying the story we might think merely of the passage into organic structures, and neglect the other and not less important changes into earth, and water, and air.

The care of the herd of Neptune would seem to imply the presence of a preservative power in Nature, 
by virtue of which, the existence of things is sustained and perpetuated; while the daily duty of counting his charge may be said to indicate the absence of any process of evolution, and to show that there is a certain and fixed number of created forms, which must be complete in order to the harmony of the whole. In favour of this view also are to be remarked the age and sleep of Proteus, for the one evidences maturity, and not infancy or youth, and the other-which, moreover, is said to supervene when the wards are numbered - argues the existence of a definitive boundary to his power and energy.

The servitude and the fatigue involved in the discharge of his duties clearly indicate dependency, and teach us that this changeful being is the personification of a law, and not the revelation of a lawgiver. His attributes, indeed, are determined and fixed by a creative power, and this is what is meant when it is said that they were the gift of Neptune.

It is to be inferred, therefore, that this fable is not intended to convey pantheistic notions, but to enunciate the statutes of Nature, and to teach their character; and hence the first lesson we learn from Proteus is, that there is a common and universal law, which, without loss or impairment, is embodied under varying outward aspects in every created form. 
The wisdom and prophetic gifts of Proteus would seem to indicate that creation and revelation are associated in a common bond of union. Nature is incomprehensible and mysterious; and that she is ordained to the communication of religious truths may be argued from the Scripture, which says that "the invisible things of Him from the creation of the world are clearly seen, being understood by the things that are made, even his eternal power and Godhead." It is evident, also, on the same authority, that all knowledge is connected with nature, for if she can explain the mystery of Deity, we may conclude that he who understands her aright will know the present and at the same time be able to look into the womb and urn of time, so as to recall the memory of the past, and anticipate the decrees of futurity.

The rest of the fable signifies the innate power of man, and his possible supremacy over subordinate creation, together with the mode by which he is to attain to this high dignity. It was necessary to seize the demi-god in the daytime, and to struggle with him through all his changes until he again appeared in the form of man, and then the mastery was gained; and this is told in order that we may understand our true position in the universe. The story implies, that it is in nature living and moving, actuated by continual change, and illuminated by the light of day, and not in midnight porings over 
books, or in lonely musings upon death, that the ruling law is to be found. It implies, also, in the manner in which the metamorphoses terminate when the contest had been successful - that the true essence of no single thing can be understood unless the embodiment of unity be pursued through all its windings until it culminates in man. And, finally, the exertions necessary for victory indicate that a something more is required than the mere passive reception of truth, and that man must have a long struggle with himself before he can win the dominion over Nature. This is the story of Proteus, and its significance.

It would appear, therefore, that the poetical philosophy of ancient times, and the successes and aspirations of modern science, alike direct our attention to a parent and fundamental idea in the works of Nature, and at the same time encourage us to strive for its discovery.

Such is the lesson which is taught us by the past and the present: and now, therefore, the question which we have to ask is, whether it is possible to move onwards, and to realize the high doctrine which is indicated? In part, at least, we may answer in the affirmative; and we may add, further, that we fail in the absolute and perfect demonstration, only because our senses are not clear enough to penctrate into the darker depths of the subject. There is no 
difficulty, however, in perceiving in outline, that there is a true and substantial unity in nature, and this not only in a metaphysical, but also in a practical sense; and it shall be our present task to communicate, as far as we are able, the arguments which lead to this conclusion.

In order to demonstrate this doctrine, the plan we propose is to seek successively for its proofs and evidences in the several kingdoms and provinces of Nature. In this inquiry we shall begin with that which is sensible and subject, or what is understood by the term matter and form, and then pass on to that which is supersensuous and endowed with power, namely, force or spirit. Under the first head our purpose is to examine the harmonies of the different parts of vegetable and animal bodies, and to proceed from one step to another, until we find the common law which reigns in every organic form; and having done this, to seek for the analogies which connect unorganized substances with living structures. Under the second head, our intention is to investigate the mutual affinities of the agencies which constitute the force associated with inanimate bodies, and then to consider the power to which the name vital is given, together with its relation to ordinary physical influences; and lastly, to speak of the connexion which exists between force and matter. 


\section{CHAPTER I.}

\section{OF UNITY IN FORM.}

THIs chapter resolves itself into two sections: in the first, the object will be to endeavour to find a common archetype in the several varieties of organic form; and in the second, to search for the same ideal principle in unorganized substances.

\section{OF UNITY IN THE FORMS OF ORGANIC NATURE.}

The principal objects to be attained point out the path to be pursued in the search after an archetypal idea in the creatures of life. To reconcile the differences in the organs of which the plant and animal are composed,- to explain the relation of these organs to the stem or trunk, so as to see unity in both,- - and to discover a common law in every living thing-are problems to be solved before the doctrine of unity in 
the forms of organic nature can become a recognised truth,- - and hence we may learn the general direction of the path along which we are about to travel, and the stages at which we may rest.

\section{I.}

A common plan may be detected in the organs of the plant; and in the parts of animal bodies which are called by the same name, the evidence of uniformity is not wanting.

1. In the plant, all the principal organs which appear above the surface of the earth are varied aspects of the same form. Goethe was the first to enunciate this important truth, and the "Metamorphose der pflanzen" is still the masterpiece in which the demonstration is to be found.

The evidence of this analogy rests on certain plain and intelligible facts which have been gathered from the commonplace history of each organ.

During the process of germination, the cotyledons are found to change into green and succulent expansions, closely allied in shape and structure to the leaves which form the plumule of the embryo plant, and in some seeds, as in the Vicia faba, true buds are found in the axils of these organs: and hence there is sufficient reason to suppose an analogy between the cotyledon and the leaf.

In the date tree (phœnix dactylifera) the leaf 
passes from the state of a simple undivided disk to a form which rivals a true branch in the complexness of its parts; and from these changes we learn to discover the common nature of the simple and composite varieties of the organ. The petiole, also, or the basal part of the leaf, is of an analogous character,-for in different plants, and the orange-tree in particular, there is a marked tendency in this part to change into the familiar form of the leaf.

The organs of the flower and the leaf are truly correlative. Even the crown-like arrangement of the parts is not peculiar to the former, for in the genus Pinus, and in many other instances, the primary leaves simulate flowers by the manner in which they are placed upon the stem.

The wreaths called "floral-leaves," which frequently enclose the flower, are composed of true leaves, and the involucres of plants, such as the common sun-flower, or marygold, are formed of elements between which and the ordinary leaflets every possible gradation may be traced upon the same stalk.

The analogy of the floral envelopes to whorls of true leaves is very evident, if we examine the variations which they assume. Ordinarily the petals are tinted with the hues of the flower, and the sepals are green like the leaves; but this distinction is by no means constant, and in many instances the latter organs are coloured in certain parts of the surface, or 
at the edges or tips, while at the same time the texture is more delicate and petaloid than usual. Within the calyx of the common pink, for example, there is often a second calyx tinted and changed in this manner. Sometimes, also, the leaves of the stem may be transformed into a corolla without the intervention of any calyx, or, what amounts to the same thing, the corolla may be absent and the calyx so like the corolla in its characters, that the difference cannot be detected by the senses. Sometimes the common leaves of the stem are coloured in a greater or less degree immediately before the period of flowering, or the leaves in the neighbourhood of the flowers may be constantly decorated in this manner. On the stem of the tulip, again, there is often an anomalous organ intermediate between the leaf and the petal, which is green in the part contiguous to the stem and coloured like the petal in the remaining portion.

The vague and ill-defined organs, known under the name of nectaries, afford a natural passage from the corolla to the stamens; or an analogous mode of transition may be found in the changes which have taken place in various double flowers. In many species of the rose, for example, in the midst of petals perfectly developed and coloured, are seen other petals formed in such a manner as to resemble the filament and anther of the stamen. Certain double poppies, also, very frequently present perfect anthers on some of the 
petals, and antheroid tumours on other's; while at the same time there is a disposition in the discoid surface of these organs to shrink into the form of the filament.

Nor are the stamens distinguished in any absolute manner by the possession of the pollen of the anther. The pollen in its most perfect condition consists of minute grains containing a fluid; but in many instances the grains are absent, and the fluid-which is the essential constituent_exudes as a free liquid secretion which cannot be distinguished from the other humours of the part: and therefore, with Goethe, we may conclude that the juice of the pollen, or anther, so far from being a peculiar and specific product, may only be a more highly elaborated form of the juices which appear as the honied or odorous secretions of the nectaries, or petals, or leaves.

The common nature of the pistil is not less certain, though somewhat more obscured and hidden from our notice. In the crocus, for example, the stigma, or upper extremity of the organ, is green and absolutely similar to the elements of the calyx; and in the double poppy, the same part has the form of small and delicately coloured leaves, precisely similar to the petals. In the Iris and Ranunculus Asiaticus there is a true petaloid transformation of the stigmata, and also of the styles, or intermediate portions of the 
pistil. And lastly, the ovary itself, or the essential part of the pistil, is an altered form of the same element. The leaf-nature of this part is concealed, it is true, in fleshy and succulent or in woody and hard fruits, but even in these cases it cannot escape our investigation if we trace the organs to "the earlier periods of their history. Or the real nature of the ovary may be discovered in plants, such as the common pinks, where it is a very frequent phenomenon for the seed-organs to be metamorphosed into a calyx, the divisions of which bear on their extremities the traces of the former styles and stigmata, while at the same time new flowers, of a more or less perfect character, are developed in place of the seeds.

Nor is the ovule-producing faculty of the ovary absolutely distinctive of this organ. The ovule, indeed, is a germ intimately allied as to its essential nature to the germs produced on the fronds of ferns, and to the buds on the leaves of plants, such as the Bryophyllum calycinum and Phyllocactus. It must be observed, also, that there are many true ovaries in which the carpels are imperfectly closed, and the ovules exposed like the germs of the frond and leaf-in which, in fact, the germ-producing carpel can scarcely be distinguished from the leaf or frond. The pistil, therefore, cannot be considered as a peculiar and specific organ. 
The immediate coverings of the seed are other aspects of the same archetypal form. The flower-bud and the axillary leaf-bud are intimately related to each other, and in the comprehension of the truth of this analogy we discern the nature of the coverings of the seed. It would appear, indeed, that the two varieties of buds are reciprocally transmutable, for such would seem to be the conclusion, from the well-known fact, that a plant will produce leaves instead of flowers, if abundantly supplied with food, and flowers instead of leaves, if the allowance of nutriment be restricted. In some monstrous and accidental forms of vegetation, moreover, the characters of the two buds are interblended in one and the same instance. The rose, for example, is very prone to such anomalous productions, and here we may often see the metamorphosis which has been described by Goethe. A bud, destitute of any outward marks of distinction, is seen to open into a perfect calyx and corolla, and then to give birth to a stem, in place of the ovary and the circlet of stamens. This central and unnatural growth is gradually developed, and at length becomes a branch, furnished with the usual appendages of hairs and spines and leaves, together with shrivelled and imperfect petals and stamens and buds, which themselves expand in time into flowers of the same abnormal character as the parent. In this metamorphosis, therefore, the flower-bud changes into the leaf-bud, 
and then again reverts to its former condition, and the difference of the two is completely lost.

But further, the seed and the bud are found to interblend in a common idea. Indeed, if we descend to the more rudimental forms of vegetation, the differences of these organs escape the investigation of the most attentive observer. In the more perfect plants, true seeds most undoubtedly exist, and the presence of true buds is not to be denied; but if we extend our inquiries, and include all the varieties of these organs, it will be found that a point exists where true seeds cannot be distinguished from buds, which are detached from the plant-mother like true seeds, but which originate independently of any floral influences. And hence the seed is analogous to the bud, and as the consequence of this analogy, it may be presumed that the immediate envelopes of the seed, and of the bud, are of a similar nature; and as the coverings of the one are rudimentary leaves, aborted and altered, so as to provide a warm cradle for the tender embryo during the winter, so also we may conclude that the vestments of the other are leaves similarly changed.

The cotyledons lie immediately within the tunics which have just been described, and thus we reach the point from which we started. In our circuit, the principal organs of the aërial system of the plant have passed in review; and as the result of the examination, it may be stated, that cotelydons, and leaves, 
and bracts, and sepals, and petals, together with the immediate envelopes of the seed, are all correlated and analogous forms.

Such is a free sketch of the arguments of the "Metamorphose der pflanzen," by which the poet-philosopher of Germany has demonstrated the presence of unity in the organs of the plant which have successively occupied our attention.

In this enumeration, however, no mention has been made of certain organs which would have opened the way to the knowledge of a unity embracing the parts buried beneath the earth, as well as those which are more exposed to observation. Of the parts, the omission of which is of such consequence, the more important are the tendril and the aërial root,-and of these we now proceed to speak.

The tendril is a transitional organ, which cannot be assigned with strictness either to the terrestrial or aërial system of the plant. The connexion with the leaf is seen in the frequent transformation into this organ, or else in the substitution for it, while, at the same time, the simple form, and the tendency to cling to foreign bodies, reveal the root-like character which is inherent. In the more unusual forms, however, as in the Asplenium rhizophyllum, may be found the direct realization of this double nature. In this case, indeed, the identity with the true aeirial organ is evident from the connexion with the leaf-of the median 
nervure of which the tendril is the direct prolongation; while, on the other hand, the downward direction of growth, and the manner in which it eventually becomes buried in the earth, reveal the other, or rootlike nature.

The aërial root is of analogous import. The leafnature in this case is very apparent in the Orchedacean family, and especially in the Vauda teres. In this plant the aërial roots, and the representatives of the leaf, exist as simple rounded and elongated soft spines of a green colour, between which the mutual resemblance is such, that the one might readily be mistaken for the other. In the Pandanus, again, the history of the growth of the plant shows that there is no essential difference between the aerrial and the common root. In this case, the original and true roots perish after a certain time, in consequence of the pressure caused by the growth of the aërial roots; and, contemporaneously with the process of destruction in the former, the latter increase in size, sink into the ground, and eventually take upon themselves the function of their predecessors. In their turn, these perish in like manner, and are replaced by analogous organs; and in the fact, therefore, that the aërial roots succeed to the office, as well as share the fate, of the common roots, we have an argument which obliges us to admit the essential analogy of these organs. This central death, and centrifugal birth of 
the elementary parts, is a universal law of growth in the terrestrial system of the plant, and in this or any other respect, there is no peculiarity of organization in the Pandanus. In this case, however, the phenomena in question are very conspicuous, and the history may be studied in all its stages, without any diffculty. When full grown, indeed, the Pandanus presents the singular and almost unique spectacle of a tree raised high in the air upon a circlet of stilt-like roots, and having beneath it a cavity large enough, in many instances, to afford a shelter and home to monkeys, or to animals of larger size.

From the history which has just been narrated, we may conclude that the aërial root is a true root, if it reaches the ground; while, on the other hand, from the obvious relation to the leaf, as seen in the Vanda teres and Asplennium rhizophyllum, (for the tendril in this case may be considered as an aërial rootlet,) we may infer that this organ may be ranked in the same category with the several members of the aërial system of the plant.

The common nature of the rootlet and leaf may further be argued from certain passages in the life of the plant. It would appear, indeed, that the respective characters of the organs are due to the peculiar conditions in which they are placed, and that every ground of difference and distinction may be abolished by the simple transposition of these conditions: thus, 
a branch is changed in its nature, and rootlets, instead of buds, mark the operation of the vital processes, if it be buried in the ground during the season of growth-and, on the other hand, an opposite metamorphosis takes place, and leaf-buds make their appearance if a root be placed in the natural conditions of the branch-if, that is to say, it be exposed to the more genial influences of the atmosphere. When taken in connexion with the history of the tendril and aërial root, the significance of these facts can scarcely be misunderstood, and the only construction of which they are susceptible would seem to be this-namely, that the parts which can undergo this reciprocal metamorphosis must be related to each other in the most intimate manner.

The common nature of the rootlet and leaf may be argued also from certain natural changes in the vegetable economy, which seem to indicate that a common branch may undergo a partial transformation into a root, and then pass back again into its former condition. Such a metamorphosis has place in the winter, and it is evident, from an unprejudiced analysis of the facts of the case, that it is no idle dream of the fancy to suppose that the branch, denuded of its summer dress of leaves and flowers, is at times an aërial root.

The possibility of a change of this nature at this season may be inferred, if we consider the altered 
circumstances under which the branch is placed. There has been, in fact, a change in the conditions of life, in some measure equivalent to that which affects a growing shoot, when this has been separated from the parent, and buried in the ground. To treat a branch in this manner during the period of growth, is virtually to exclude it in great measure from the light and heat, and other vivifying agencies. Nor can it be doubted that the metamorphosis which takes place is consequent upon privation of force, if with this we compare the opposite change, and analyze the circumstances which effect the transformation of a root into a branch, or which cause the wintery spray to be reclothed with verdure. In either case, indeed, an intensification of force is the efficient cause of the metamorphosis. When, for example, the earth is removed from a root, the barrier is taken away which obstructed the vivifying influences, and as no change ensues if the exposure be made in the winter, it is reasonable to ascribe the quasi-transformation into a branch which the root undergoes, under these circumstances, to the intensification of the influences of the outer world. The branch, moreover, remains leafless and barren so long as the winter continues, and, in this case, it cannot be doubted that the prime agencies in the restoration of its vernal honours, are the genial influences which attend the advent of spring. On 
direct and indirect evidence, therefore, it may be argued that the branch is transformed into a root by the privation of its vivifying influences. And as the branch in the winter has been subjected to a change in the condition of its life, in which there is an undoubted abstraction of force, we may infer on this ground that the partial transformation into an aërial root is a possible event at this time.

In relation to function, also, it would appear that a branch may undergo a complete metamorphosis, and from the movements of the nutrient fluids at certain times during the winter season, it is to be argued that the aërial organ may actually discharge the duty which generally belongs to the root. We possess, it is true, no very definite information as to the motion of the sap, but the facts which we have are at least sufficient to show the existence of certain important changes. Thus, on making a section of a tree in summer, the sap is seen to well up in abundance from the surface of the stump, while that of the trunk remains dry, or, in other words, there is evidence of a powerful current from the roots towards the branches; but on performing a similar experiment during a hard frost, the surface of the stump remains dry, while that of the trunk drips with moisture,-and on this occasion, therefore, the results are entirely opposite, and the current of sap moves from the branches towards the 
root. The upward movement of the sap has been often observed; but the downward movement, on the contrary, (so far as I am aware,) has only been noticed by M. Biot. From the observations of this experimenter, however, as quoted by Dr. Lindley, it would appear that indubitable evidence of the downward current was found in the trunk on the section of a pollard of considerable size, and also in an actual exudation of sap from the spongioles, which was observed and tested by means of an apparatus devised for the purpose. M. Biot, also, was enabled to decide that the downward current had place only during the actual continuance of frost, for as soon as a thaw commenced, he found, by means of the apparatus attached to the spongioles, that the exudation of fluid gave place to the opposite process of absorption.

It would appear, therefore, that there are certain ebbs and flows in the main current of the sap, and from these we may argue equal changes in the parts which the branches and roots have to play in effecting these movements. The function of the root cannot be exclusively that of imbibition, for at times there is an actual exudation of sap from this organ. It is clear, also, that the function of the branch must ever be opposed to that of the root; and it is to be argued, therefore, that the former will be an organ of absorption, or, in other words, will exercise the function supposed to belong to the root, whenever the sap has 
a downward motion. And as the summary of the whole, it may be inferred that during frost the bare branch is actually an organ of absorption, like the root at other times, - and thus, in relation to its function, the transformation of a branch into an aërial root in the winter, becomes not only a possible but even a probable event.

In conclusion, we might cite as additional evidence of a common nature in the elements of the stem and the root, the existence of those intermediate structures which botanists can scarcely decide to assign to either system. It is not necessary, however, to trespass upon doubtful ground for evidence in proof of the essential analogy of the organs of the terrestrial and aërial systems of the plant.

2. The common prawn (Palcemon), may serve as an initial lesson in the unities of the organs of the animal. In the central regions of the body of this creature, the organs are developed into prehensile limbs, and into legs which serve for purposes of progression; and in the cephalic and caudal regions, on the one hand, into the oral and manducatory appendages, and the more delicate instruments of sense, as the antennæ and eyes, and, on the other hand, into the rudimentary false legs to which at times the eggs are appended. The organs in this case may, without difficulty, be related to those which are more perfectly developed in higher phases of being; and yet, at the 
same time, the original conformity to a common archetype is not lost. The antennæ, for example, articulated and terminated by filaments, are closely related to the jointed and bifid legs. The pedunculated and ramified eye is but another and slightly altered copy of the antenna. The outer foot-jaws, also, which are longer than ordinary, resemble the common limbs immediately behind them, and the instruments of sense which are in the neighbourhood. While between the outer and inner foot-jaws, and between the latter and the false abdominal legs, the fundamental analogy may be traced without any difficulty. Whatever, indeed, may be the function, and whether highly developed or rudimentary, it is scarcely possible to examine a prawn without being convinced of the essential conformity to a common archetype of all the organs which spring from the trunk of the animal.

As we pass through the lower circles of the province of articulate nature, the appendages are more and more similar in their characters; and when we arrive at the simpler radiate animals, all sensible differences may be said to have disappeared. Ascending, on the other hand, the features of distinction become infinitely varied, but with the key found in the crustacenn animal, the protean spirit may be unmasked in every difference.

From the limb of the prawn, for instance, we may 
trace the common type onwards to the leg of the insect, and hence through the wing-like legs of many of the Mantes to the ordinary form of wing, and eventually to the jointed and folding wings of the locust. Between these organs and the fin of an osseous fish, the analogy is very immediate, and thus, introduced into the higher section of the animal kingdom, we may pass in a progressive and well-known series of changes from the fin of the fish to the highest of all appendages - the hand of man-an organ in which the separation into fingers is an exhibition of the tendency to radiation common throughout, and which in itself may be considered as a connecting link between the instruments of sense and motion. The eye of the shark, also, is an organ in which we may readily recognise the crustacean original, for it can scarcely be doubted that the ophthalmic peduncle and the double pupil, in many members of this family, are conditions transitional to the pedunculate and compound eyes of the squill and lobster. Again, from the highly-developed visual organ of the vertebrate animals, with its complex apparatus of nerves and muscles and vessels, and the strongly-fortified protective cavity, the eye of the cuttle-fish serves as an intermediate and connecting link by which we are enabled to pass to the simple ocellus of the ordinary mollusc, where the condition of form is but slightly removed from a simple nervous papilla; and in this manner we may 
detect an analogy between the extended surface of sensory papillo in the skin of man, and that surface of sensory papillæ which constitutes a compound eye in the insect tribes. A oneness of type may thus be seen in the highest and lowest of these appendages: and we may trace, in unbroken gradation, the noblest of organs, until in the papilla it is about to merge in the common formative element of the organism-the cell.

The essential oneness of type in the inner and outer organs of animal bodies may be seen at one and the same time in the higher forms of the radiate class of animals, as in the star-fishes. By reason of their rudimental characters, the inner appendages of these creatures are especially suited to the exhibition of the ultimate conformity of organs to a common archetypal element; while at the same time the degree of actual development suffices to reveal, in no undefined outline, the shadows of the forms which are assumed in the progress of ulterior evolution.

The principal internal appendages of the star-fish are, as it were, ramified extensions of the stomachal cavity. When viewed from without, these processes, as they lie in the peritoneal or respiratory sac, are no inapt representatives of the branchial or pulmonary tufts of the higher animals: while, internally, the same organs, in virtue of their central branched cavity, may with equal propriety be considered as the 
analogues of glands. When viewed in relation to function or office, these analogies derive additional confirmation, inasmuch as there is reason to believe that these parts exercise the joint functions of stomachs and glands and lungs. The visceral appendages of the star-fish, therefore, may be supposed to afford a focal point, in which several of the more important internal organs of the higher animals, namely, the glandular and the respiratory, blend into a common element. The general characters of the parts in question, moreover, are well calculated to show the real analogy between the inner and the outer varieties of the appendages. Thus, the branched character is evidently transitional to the type which is fully realized in the outer limbs of other radiate animals, as the Gorgonocephalus and Comatula; and the symmetrical and stellar disposition is not only transitional to, but identical with, the plan of the outer system.

The parts which rank next in importance are the tecth. The analogies of these organs are varied, and of great interest, but to them we can but spare a passing allusion. It may be seen, however, on the most cursory examination, that the teeth are important connecting links between the several varieties of organs, both internal and external. The general relation to the rest is seen, for instance, in the disposition upon the radiate plan, which is common to all parts, - the particular relation in the 
largely developed, calcified, and tooth-like spines, which are the ordinary forms of outer appendages in the globular echinoid animals; and so the tooth may be supposed to be an internal organ transitional to that variety of limb which is seen in the spine of the sea-urchin.

The nervous and vascular systems, which are developed in correspondence to another part of the visceral sac, will be found to furnish the parts which remain to be noticed. It is contradictory to our prejudices to regard the ganglia and centres of the nervous and vascular systems as organs, analogous to those which have already been considered; but the result of the examination, even at this early stage of our enquiry, will be to establish the probability of such an analogy. The analogy at present is mainly dependent upon two arguments; in the first place, the ganglia and vascular centres of the star-fish are arranged in conformity to the common and universal plan of radiation; and, in the second place, there is a disposition in the nerves and vessels given off from these central or focal points of the nervous or vascular rings, to ramify, and so to present a phenomenon which is suggestive of the radiate tendencies of the visceral organs and outer appendages.

The extreme rudimental condition of the nervous and vascular systems in these creatures forbids, however, any direct evidence either contrary to, or 
confirmatory of, this analogy. Here, indeed, we cannot conjure into existence the evidence which is necessary to substantiate, though we find somewhat to confirm; and as to the main objection which will at once suggest itself in connexion with the functional attributes of a ganglion or vascular centre, it may be answered that there is a diversity of function in organs, the analogy of which is demonstrable, sufficient to justify the belief in the possibility of any further difference in this respect. Moreover, it must be remembered, that organs in which nerves and vessels are very conspicuous elements, have been seen to conform in type, and hence it may be allowable to deduce an argument in favour of the opinion in question. The facts and considerations upon which the perfect demonstration of the analogy is rested, lie hid, however, in a more advanced page of the chapter.

It is not our purpose to show in minute detail how the conclusions drawn from the organization of the star-fish derive confirmation on every hand in animals higher in the scale of being. Such a demonstration, however, would be by no means difficult. In the highest creature, indeed, if we study the process of development, it will be found that the most complex of the internal appendages_-be these lungs or liver, as well as the more insignificant glandular organs-are in the beginning indistinguishable from each other, and in point of form and character perfectly analogous to 
the branching visceral processes of the star-fish. The symmetry of the circular or radiate plan is disturbed in after-life, by the abortion of some parts and the excessive growth of others, but in the primordial epoch of development it is seen that the correspondence extends even to that symmetrical disposition of parts which is distinctive of the radiate animals.

The general characters of internal and external organs seem, however, to disagree in one particular,the one class, for the most part, being hollow and tubular, and devoted to secretory purposes; the other, most generally solid, in the sense that instruments of sensation and motion are solid. The two interblend, however, in the most insensible manner, and it may readily be understood how very slight a modification in the process of development will determine the production of either variety from the same archetypal element. $\Lambda$ t the regions of the body, indeed, where the inner and outer surfaces become continuous, the characters of organs are often truly intermediate and transitional. In the poison-fang of the serpent, for example, is found an admirable illustration of this intermediate form-hollow and tubular, on the one hand, so that the tooth may seem the calcified prolongation of a glandular orifice-articulated and moveable, on the other hand, so as to present a striking approximation to the characters of the outer limb, particularly of the lateral jaw of animals belonging to 
the articulate division of the kingdom of nature. Another illustration, of a parallel character, may be found in the relationship of the branchial and pulmonary organs to a common and fundamental archetype; for it is well known that the same element by-as it were-an accidental and very trivial diversion in the process of development, may in one case become a gland-like pulmonary lobulet, and in another case a branchial tuft.

\section{II.}

The problem which concerns the nature of the stem or trunk is of great complexness; but the solution is possible, and in the end it may be shown that the central systems of the plant and animal are products of the archetype that is found in the organs.

1. The leaf-nature of the stem is plainly revealed in many members of the Cactacean family, and more especially in a common Phyllocactus. Here, indeed, the stem is formed from the leaf by a visible process of growth and coalescence; and in a plant of ordinary magnitude, we may witness at one and the same time every intermediate phase between the green and succulent leaf-organ, covered with rudimentary buds, and attached only by a narrow neck to the parent, and the brown and woody and budless stem, of which the constituent elements have coalesced so perfectly, that the lines of union are no longer distinguishable. 
In so far as concerns its shape, and the manner in which the vessels are ranged upon the surface, the quasi-leaf of a Phyllocactus must be regarded as a true leaf. The only peculiarity, indeed, which might seem to-cast a doubt upon the correctness of this analogy, is the power which it possesses of giving rise to buds; but in this respect, as is often the case, the very exceptional character is the best proof of unity. So far from being a peculiarity, it may be shown, indeed, that every leaf has a similar endowment. What, it may be asked, are the processes which cause the edge of a simple leaf to be notched and irregular, and what is the significance of the leaflets of the composite organ? No other interpretation can be offered than this,-that the processes are the rudiments of the germs which are developed into the leaflets; and the summary of the whole must be, that an infinite number of germs exists potentially in the leaf. Buds, also, are constant elements in the leaves of the Bryophyllum calycinum and Malaxis paludosa; and they are not unfrequently developed in the leaf of the orange after this has fallen from the tree. Ovules, also, or buds in another form, are normal products of growth in the carpel, which is an organ of undoubted affinity to the leaf. The ground of apparent exception is, therefore, the proof of unity, and when interpreted by its natural affinities, there is every reason 
to regard the quasi-leaf of a Phyllocactus as the perfect analogue of the true leaf.

The examination of the structure of the stem in a Phyllocactus is sufficient to establish the strictest analogy between it and the stem in other forms of vegetation. Everywhere, moreover, the stem is composed of zones or internodes, which are substantially of the same nature as the quasi-leaves of the cactacean. The argument in favour of this analogy, which is next in importance to the conformity in internal structure, is the power of producing buds, and this argument is the more important, as it shows at the same time the connexion of the internode with the leaf. The phenomena of growth may be said to afford a sufficient proof of the existence of such a faculty; but additional evidence may also be found in the rudimentary and undeveloped buds which are scattered over the surface of the internode in most instances. In the succulent Euphorbiacex, for example, traces of imperfect buds are as common as in the cactacex. In the Chamœrops and Bamboo, the joints of the stem present numerous minute processes, the germ-like nature of which is seen by the sprouts which often form in these places, when the plant is made to assume a horizontal position. On the pseudo-bulbs of the Orchideans, also, the traces of similar processes are to be found; and, finally, in every stem, though the fact 
may not be so apparent as in the instances which have been named, the possible appearance of 'adventitious buds' is still the evidence of the potential existence of the same faculty. In these facts, then, we may derive additional confirmation of the true analogy of the stem in the Cactacean, and in every other form of vegetation.

The history of a Phyllocactus, therefore, is the common history of the plant, expressed in linguage which cannot be misunderstood; and from it we learn, as the general law, that the stem is devoid of individuality, and that it is merely another aspect of the archetype which, proteus-like, is present in every organ of the plant.

In conclusion, a word remains to be added in completion of the history of the root. Already we have seen the general analogy between the terrestrial system of the plant, and the organs of the branches, and now we are able to confirm the correctness of this analogy by the possibility of resolving the stem into the common archetype. And finally, we may cite the intermediate and doubtful organs, such as tubers and rhizomes, as direct proofs of the manner in which the stem interblends with the root, or the root is transformed into the stem: and thus we may complete the evidence of the essential unity of every part in the aërial and terrestrial systems of the plant.

2. In the animal, also, there is reason to suppose 
that the trunk is related to the organ in a manner similar to that in which the stem corresponds to the leaf.

There are many instances, for example, in which certain regions of the trunk conform to the character of the appendage in the absence of visceral cavities, and in the presence of many features of positive resemblance. In the lobster the caudal region is metamorphosed into a true organ of motion. The long and slender poison-spiked tail of the scorpion is a limb devoted to another purpose. The tail of the vertebrate animal, also, is a portion of the trunk reduced to the level of the appendicular organ, and exhibiting endless transitions to the character of the common limbs-ramified and fin-like, in form and function in the rudder of the fish; tactile and a true organ of prehension in many monkeys.

In the region of the head the ordinary zones of the trunk have undergone the most perfect and complete metamorphosis, but even here we find the traces of the limb. Among invertebrate animals, for example, the anterior suctorial disk of the leech may be considered as a partial transformation of the cephalic region into a limb, in some degree analogous to the lateral extremity of many larvæ. And as instances of a similar alteration among vertebrate animals, we may cite the sucker of the lamprey, the weapon of the swordfish, the snout of the gavial, the bill of the swan, 
and the proboscis of the elephant,- - for the sucker, or sword, or snout, or bill, or proboscis, represents the extension of the cephalic axis as well as the parts in connexion with the mouth of these animals.

It is needless, however, to depend upon illustrations, the significance of which is in any measure doubtful; for even if it be not possible to adduce any instances of an actual metamorphosis of the head, or of part of the head, of an animal into a limb, we may at least succeed in demonstrating the abstract possibility of such a change. A community of nature, indeed, has been shown in every part of the trunk, and hence it follows that an alteration similar to that which has place in the tail may be predicated also of the head and of any other region.

The history of fissiparous multiplication, as seen in the Nerëis and in other annelidans of the same family, is the sole argument necessary to prove a common nature in every region of the trunk of an anellose animal. As the word signifies, this mode of multiplication implies a division by fissure of the parent animal, and a transformation of the sections into the progeny. The worm-like creature which is the subject of this strange metamorphosis is seen to become marked by certain transverse constrictions, which gradually deepen, until the complete disseverance of the animal, while at the same time, the portions in- 
cluded between the lines of division are transformed by degrees into forms like the parent. The act of disjunction does not take place until the offspring are fitted for independent existence, and so it is that immediately before the moment of quasi-regeneration the parent presents the singular spectacle of a series of similar animals of smaller size, threaded together like beads upon a string. In this strange process certain of the central and ordinary zones of the trunk are seen to become developed, on the one hand, into forms characteristic of the cephalic region; and to shrink, on the other hand, into the rudimental state of caudal elements: and in this history, therefore, we have a direct and sufficient evidence of the unity of the anella in every region of the animal.

Whatever difference of opinion may exist with respect to the special analogies of parts in different vertebræ, there is none as to the general fact, that the vertebræ in every region of an animal are the products of a common original. This particular mode of unity has been verified in every form of vertebrate life, and it is now a settled doctrine professed in the schools of anatomy.

A common nature, therefore, may be assumed to be present in the zones of every region of the animal, vertebrate as well as anellose; and hence we may conclude that a transformation into the character of a 
limb in the caudal region is the proof and evidence of the possibility of a like change in the cranial and other regions of the animal.

The appendages of the animal, also, are seen to conform to the characters of the body, in so far as concerns the presence of visceral cavities: and thus, as on the one hand a part of the body may assume the character of the appendage, and lose, by so doing, the visceral cavities, which were its chicf ground of distinction, so, on the other hand, the opposite change may take place, and the appendage simulate the body by the acquirement of these cavities.

To understand the possibility of this change it is necessary to simplify as much as possible the idea of the visceral region of the body: and in order to this we must not be content to observe the form which is assumed in the higher animals, but together with this we must include also the appearances found in simpler and more rudimentary creatures. It is necessary, therefore, that we review in a descending series the several links of the two great chains of being, at the heads of which are placed the vertebrate and anellose animals, and that we form our idea of the visceral region of the body from the general contemplation of the whole.

The articulate animals, whether crustaceans, or arachnidans, or insects, or anellides, are all related to 
each other, and there can be no doubt that the visceral region of the body is perfectly analogous in each case. Of these creatures the anellides are most simple, and, as their representative, the common leech may be said to afford a typical expression of the visceral region in this province of nature.

Descending from the anellides, the leech naturally allies itself to the common sea-slug (Holothuria), and by this means we enter into the radiate department of life. Intimately related to the holothuridans are the sea-urchins, and these again merge insensibly into the common star-fishes; and thence, passing still downwards, we reach successively the Ophiurus, the Gorgonocephalus, and eventually the Comatula. In the radiate animals, the visceral region of the body is much altered-the cavity, instead of being elongated as in the anellide, becomes shorter and rounded, and the several organs which lodge in the cavity are more and more simplified, until in the Comatula we attain to a condition wellnigh as simple as in the common polype. Indeed, as we descend below the star-fish, the entire form tends to assume the radiate character distinctive of the polype, by the formation of arms or tentacles around the oral orifice-and from the manner in which the food is seized by the arms, the long-armed star-fish may be considered as a gigantic polype; and hence there is reason to conclude that 
the visceral region of the body in the articulate animal, may be traced downwards, until at last it merges in the simple polype.

Returning again, in order to descend from the other extremity of the chain of animate forms, we find that the visceral regions of the body in all classes of vertebrate animals are intimately related to each other. The transition from the simpler forms of fishes, such as the lamprey, to the highest of the molluscous animals, is a very easy task, and in the common cuttlefish there is no difficulty in determining the actual analogy of the visceral region of the body to that of the vertebrate animal. The cuttle-fish itself is a strange and mysterious creature, which belongs strictly to none of the great groups of nature. It is as much a vertebrate as a molluscous animal, and it belongs to the radiate as truly as to either; - and that the form which is the outward bond of union to the latter group is not an empty delusion, is evident from the direct transition between the shell-less acephales and the seaslugs_-between animals, that is to say, which belong, on the one hand, to the molluscous, and on the other to the radiate provinces of nature. A cuttle-fish, therefore, may with as much justice be considered as a gigantic polype as a metamorphosed snail; - at any rate, there can be no doubt of the possibility of tracing a connexion between the visceral systems of all molluscous and that of radiate animals generally. 
Tracing the visceral region into the radiate province of nature, we may pass from the sea-slugs and urchins, and the higher forms of the group, to the ciliobrachiate polypes, and eventually to the simple Hydra; and as we descend, the alimentary system is found to become more and more simple, until, as in the last named polype-all relics have disappeared, and the visceral cavity and the organs contained within it are reduced to a simple hollow scooped out in the body of the animal. And hence the little predacious hydra may be considered as a miniature copy of the fierce cuttlefish of the ocean; and in it we may find the last simplification of the visceral region of the body of the vertebrate animal.

Along either chain of forms, therefore, we descend eventually to the same point; and it would appear that the polype is typical of a visceral region of the body in the higher animals - the visceral cavity of the polype being analogous to the so-called cavity found elsewhere, and the coats of the polype as a necessary consequence to the walls of the body in the anellose and vertebrate animals.

Assuming the polype to be of this signification, there is no difficulty in finding in the appendages the proofs of an actual conformity to the characters of a visceral region.

The polype form, indeed, is revealed in every organ throughout the entire radiate province of nature. In 
the buds of the zoophyte, and in the cylindric tentacles, or pedicels, or suckers of star-fishes and sea-urchins, and holothuridans, the same common nature is ever present. In the larger limbs of the animals, as in the arms of the star-fish, the latent existence of the polype-form is evident from the changes which take place in these arms in the Gorgonocephalus and Comatula. The limbs of the star-fish, moreover, are hollow, and the cavities, which are continuous with the common cavities of the body of the animal, contain processes of the true alimentary system, - and in this case, therefore, it is impossible to deny the direct transformation of a limb into a visceral region precisely similar to that of the body of the animal.

In the articulate province of nature, the same form is reflected in all the appendages. In some of the lower ancllides, and in innumerable hosts of larvæ belonging to the higher articulate animals, the limbs, indeed, are very similar to the pedicels of the star-fish: while in the branching and pedunculate eye of the Crustacean, and in other organs of a similar nature, the limb is modified, as it is in the Comatula; or, in other words, it represents a polype in which the growth of the tentacles or arms has preponderated over the stomachic cavity. It is possible, also, to find in this province of nature certain forms, in which some of the appendages are actually similar to the visceral region of the borly of the same animal: thus, for 
example, some of the limbs of the Nymphæa are hollow, and filled with viscera, and, as in the case of the star-fish, the cavity and the contents are directly continuous with the cavity and contents of the body of the animal.

The same character is also evident in the appendages of animals which belong to the molluscous province of nature. The polype-like organs on the arms of the cuttle-fish are calculated to illustrate this fact. The eye and tentacle of the common snail may also be cited as more conclusive arguments, for, in this case, the tentacles which form the principal part of the organs are hollow, and the cavity is continuous with the general visceral cavity of the animal.

And, finally, a parallelism to the rest may be found in the appendages of animals belonging to the vertebrate province of nature, and one or other of the principal types of the polype may be detected everywhere. The type witnessed in the Comatula, in which the tentacles preponderate excessively over the visceral cavity, is seen in the tendency to radiation of the extremities of many appendages, and especially of the hand. The other type of polype, where the stomach is developed at the expense of the tentacles, is realised where we should least expect it, and in a manner which is very wonderful. Examine, for instance, the eye of the bird, and observe how strangely this instrument of sense conforms to the characters of 
a simple polype. Taken abstractedly and apart from its special function, and viewed solely in relation to the obvious law of its conformation, the eye, indeed, may be considered as a polype, the development of which has been arrested immediately before the completion of the perfect state. The mouth is not fully formed,-but yet in the pupillary orifice and in the extreme attenuation of the anterior coats of the globe, we reach, as it were, to the moment immediately antecedent to the act of opening; while at the same time the contractile iris and the ciliary processes may be supposed to represent the tentacles and arms in a state of readiness for protrusion and service the moment they are wanted. So perfect and wonderful are these features of resemblance, that the eye may seem a polype in the last stage of embryonic transformation.

The correctness of this analogy is further evident when we consider the coats of the eye. In tracing the polype to the articulate animals, the simple walls are seen to become evolved into concentric layers of a nature similar to those which are found in the coats of the eye: and in this similarity of the products of evolution, therefore, is to be found an additional argument in favour of the potential existence of the same archetype in the eye and the polype.

In every animate form, indeed, there is reason to suppose that the negan may assume a charater similar 
to the visceral region of the body in the same animal.

It has been shown, therefore, on the one hand, that certain regions of the trunk in an animal may lose their visceral cavities and be changed in other respects in such a manner as to become reduced to the character of a mere appendicular organ : and, on the other hand, that a simple appendage may be transformed by the acquirement of a visceral cavity and by other changes, so as to simulate the visceral region of the body to which it belongs: and hence we may conclude that the trunk of an animal is related to the limbs and appendages of the trunk, in like manner as the stem of the plant is related to the branches and organs of this stem.

\section{III.}

The unity of creative design in animal and vegetable forms is not obscurely revealed in nature. In the Orchidean family; the transition to the animal character is very marked-roots hang loose and free, as careless to infix themselves in the earth, and animal-like flowers tremble in the breeze as if about to escape from the stem which imprisons them. The Peristeria elata, or dove plant,-a form in which the flower is the perfect image of a dove with outspread wings embosomed in a rose-like crown of white sepals,-is indeed, the symbol of the communion of 
the plant with the higher members of the animal kingdom-the embodiment in a visible form of the dream which inspired the song of Ovid in bygone days. In the Mantis siccifolia, or the walking-leaf, on the other hand, the wings and the wing-like legs so closely resemble leaves and petals in colour and venation, that the insect seems an emancipated orchis flower. And other animals are equally suggestive of the memories of the orchidex; thus in the Balanoids, or acorn-like cirripedes, the shells are arranged in a flower-like whorl-the crustacean animal lies within this whorl, as the dove within the flower of the Peristeria elata-and the entire animal is connected with the earth by a peduncle or root.

The demonstration of the analogy of plant and animal is a problem of great complexness, and in it we are in danger of being confused by the multitude of objects that crowd upon us. It is desirable, therefore, to adopt some plan by which we may simplify our task: and hence, before proceeding to the subject of actual demonstration, we will attempt to pave the way by adducing certain preliminary and circumstantial arguments which may be deduced from the general characteristics of the organic world.

I. Many presumptive arguments in favour of the unity of organic nature may be found in the evident parallelism of the commonplace characteristics of plant and animal. 
1. In the perfect plant, the arrangement of parts in a spiral, branching, or radiate manner, together with the absence of the power of spontaneous movement, may be considered as general and universal features of organization. The presence of such characters, indeed, is involved in the very idea of a perfect plant.

2. In the animal, also, we may always discern branching, radiate, and spiral tendencies in the plan of organization. The power of spontaneous movement, which is the attribute of the higher forms of animal life, may seem, indeed, a fatal objection to the analogy of the plant and animal; but this objection is only apparent. Such a power cannot be deemed characteristic of every animal form: indeed, in the earlier epochs of the history of the nobler creatures,which epochs are typical of vegetable life,- and in myriads of forms belonging to the radiate and molluscous provinces of nature, where the plant-phases of the embryonic state of the higher animal are permanent conditions of being, not only is there an absence of the power of spontaneous movement, but the animal is actually a prisoner, like the plant; and, on the other hand, it may be observed of plants, such as the orchidians, where the affinities to the animal are close and intimate, that there is, as it were, a tendency to spontaneous movement-for the parasitical inclinations, which prompt these plants 
to forsake the earth and to cling to organic forms in preference, is, as it would seem, a first step towards freedom and independence. The parallelism of the animal to the plant in the general characters of the organic plan is seen, however, more distinctly, if we travel successively through the several ranks of being.

Multitudes of forms abound in the radiate province of nature which are assigned with equal readiness to the animal or vegetable category-forms, that is to say, which are truly intermediate and transitional in their characters. The Corallidæ are vegetables, so to speak, with flowers somewhat more irritable than those which fall to the lot of vegetables generally; - but with this exception, there is the same tendency of development as in vegetables - the same branched, stellate, and spiral disposition of organs, - and the same absence of the power of spontaneous movement. In the higher members of the radiate family, the likeness to certain vegetable forms is very strange: thus, for example, the star-fishes and sea-urchins may, without extravagance, be supposed to be the analogues of the Cactacean forms. Many of the Echinocacti, in form, in spines, and in quasi-ambulacral lines, containing polype-like buds, are, indeed, the precise images of the ordinary sea-urchin. The Astrophytum myriastigma is the representative of a short-armed star-fish, the polype-buds being arranged in lines, like the 
suckers of the radiate animal. Some of the cactacex, also, as the Mammillaria nivea v. cristata, might be mistaken for brain madrepore; others, as the Monsonia burmanii, are the images of ordinary corals; others, again, as the Rhipsales, possess a direct resemblance to the Isis Hippuris, and other articulated corals.

The mollusc typifies a very rudimental state of existence: and the various forms of these animalsso strange is the parallelism to vegetable structuresseem the counterparts of seeds animated with a more vigorous life at different stages of the process of germination. An oyster, for example, is, as it were, an animal-fruit in the earliest stage of germination, where the shell-testæ have dehisced, but where the radicle and cotyledons are scarcely at all developed. The common cockle, again, is a similar fruit, in which the germinative process is more advanced, and where in addition to the dehiscence of the shell-testr, a long foot-radicle has protruded. These forms lie loose and free upon the shore, but in other instances the organism is typical of a more advanced phase in the process of germination, and the animal is fettered to the earth by its root-like foot. In the Pholas, for example, the foot-radicle is enormously developed and deeply buried in the sand or rock which serves for the bed of the animal: and in the mussel, the same organ, though more sparingly 
developed in point of volume than in the pholas, is securely affixed to the earth by means of the spongiolefibres of the byssus.

The general form of the lower members of the molluscous group tends to roundness; and in this respect, therefore, there is an additional correspondency with the seeds and fruits of the plant. In the higher members of the group, and especially in the gasteropods and cephalopods, the characters of the organic plan are more perfectly manifested; and here, in the helical shells, which are of such constant occurrence, and also in the radiate and branched disposition of organs, especially in the tentacles and tentacular polypes of the cuttle-fishes, the conformity to the vegetable plan of organization is very obvious.

The more rudimental creatures of the articulate group of animals, as the ordinary tæniæ, agree with vegetable forms in the similarity and independence of their segments, and for the most part, also, in the absence of the power of spontaneous movement. The more elevated forms are far removed from these characters in their most perfect state of development; but in the infant, or larva condition, the very highest of these creatures-in the long worm-like body, in the uniform character of the segments, and in the frequent attachment by means of a byssus-like thread - correspond very closely to the simple and regetable type of the tania. In the arachnida, which are the 
persistent representatives of the active pupæ of insects, the spinnaret and the thread still remind us of the root. In the hermit crab, the prehensile tail of a crustacean may be said to serve the purposes of a root in infixing the animal in the disused shell of some conchiferous animal. The spiral characters of the organic plan are illustrated in articulate animals in a thousand instances_-in the coiling of the sleeping myriapod,--in the spiral proboscis of the butterfly,in the filament of the tracheal tubes of insects: and the branching character of the same plan is not less obviously apparent; as, for example, in the compound eyes of crustaceans and insects.

The forms of the vertebrate sub-kingdom of nature, in the process of initial development, pass through a number of stages, which correspond not only to the lower phases of animal existence, but also to the still lower phases of vegetable life. The membranes of the ovum of the mammal-actually transformed to shell in the extruded eggs of the majority of the oviparous vertebrate animals_may be considered as analogous to the shells of molluscous animals and vegetable seeds; and if so, then it follows that the umbilical vesicle may be analogous to the foot or radicle, and the cord and placenta to the infixed root and rootlets.

In the fotal stage of existence of the vertebrate animal, the organism is as destitute of the power of spontaneous movement as it is in the plant, and 
the food necessary to existence is supplied, moreover, by an organ which acts like a true root. Indeed, it is only in the after-periods of its history that the animal is emancipated from this plant-like thraldom.

The several remaining general characters of the organic plan which were enumerated in the plant, and which have been traced throughout the subordinate provinces of animate nature, are repeated also in vertebrate animals. The tendency to spiral growth is evident in the curves of the tail in the leopard, or of the proboscis in the elephant, and also in the coils of the body of the sleeping serpent; it is evident, also, among organs, in the horns of the ibex, or in the alimentary canal of the shark; and, finally, it is evident among the ultimate formative elements in the spiral nucleus of many independent cells. The stellar or radiate tendency of the same plan may be seen in the caudal fin of an ordinary fish, or in the anterior sucker of the myxine or lamprey - it may be seen, also, in the separation of the hand into fingers, or of a gland into branches-and, finally, it may be seen in the simpler products of the archetypal form, as in a ciliate cell-the appendages of which, indeed, are calculated to remind us of the tentacles of a polype, and to suggest an analogy between an epithclium clothed with such cells, and the surface of a zoophyte covered with polypes. 
II. In plant and in animal it has appeared that no absolute and essential distinction can be placed between the central systems of the stem or trunk, and the appendicular organs; and in each, therefore, a peculiar archetype may be supposed to exist.

At present, however, this archetypal element is but a vague and uncertain idea; and if we descend to special inquiries, a host of ulterior facts remain to be weighed before it can be received as a determinate entity. At once, indeed, important and wellnigh insuperable difficulties start up in the mind. It would seem that there is an essential difference in the special plans of the nervous, and vascular, and muscular, and osseous systems of which the animal frame is constituted. It would seem that there is an irreconcilable distinction between the zones of the vertebrate and anellose groups of animals. And, finally, notwithstanding the possibility of resolving plant and animal each into a peculiar archetypal element, it is by no means proved that this is the same in each case.

Such are the main difficulties which arise when we endeavour to realize the idea of unity in organic nature, and which have to be surmounted before our task is ended.

Before we enter into the lists in order to strive against these special objections, it is desirable, however, to provide an answer to a preliminary question 
in connexion with the vertebra, which question will be found to concern the heart and life of the three major difficulties that have been named.

The vertebra and anella-regarding these terms as expressive collectively of the nervous and vascular, as well as the osseous and remaining parts of the organic element_are supposed to differ in a very essential particular. The anella, on the one hand, is a ring of a single cavity: the vertebra, on the other hand, is a composite ring, formed, as it were, of several minor rings ranged around a central solid part, to which the name of "body" is given. The existence of the solid centre in the one case, and the absence in the other, is considered as an essential ground of difference between the vertebral and ancllose zones, and the nature of the body of the vertebra is that initial problem which is of so great importance to the solution of the rest.

What, then, we will ask, is the nature of the body of the vertebra? Whatever may be the perfect answer to this query, of this it is evident-namely, that the position in the zone to which it belongs is not necessarily central, and also that all traces of its existence may at times disappear. Such, indeed, are the changes which are noticed when its history is specially examined, that - strange as it may seem-the very presence of the part is in the end a potent argument in favour of 
that unity to which at first it seemed so fatal an objection.

Properly speaking, the thoracic vertebræ of the chelonian reptiles may be said to be destitute of true "bodies," for in this case the place of these supposed central elements is occupied by thin and narrow belts or arches, while at the same time the processes to which the office of the bodies would seem to be deputed are removed behind the spinal cord. In the head of the same animal there is a similar deficiency, and the place of the solid centres is supplied by the imperfect plate of bone that forms the floor of the skull: and in the upper cervical vertebra or atlas, also, there is still the substitution of the simple arch, without any central and definitive mass of bone.

An imperfect and rudimentary condition of the "bodies" of the vertebræ of the trunk is seen, moreover, in many other animals. In fishes, for example, the ends of the vertebral centres are deeply excavated, and in some of the more rudimentary forms of the cartilaginous group these excavations are completed, and a continuous canal runs from one end of the vertebral column to the other; and in addition to this, the same centres are often cut up into distinct segments by means of deep fissures on the external surfaces. In some cetacean animals, also, as the seacow (Manatus), the bodies of some of the lumbar 
vertebræ are partially divided into two lateral masses by a deep groove; and in man himself the traces of a similar division may be found in the same region.

Nor are we to consider as at all peculiar the conditions of the atlas and cranial vertebræ in the tortoise. In the majority of vertebrate animals, indeed, the body of the atlas is more or less imperfect. For the most part, also, the bodies of the cranial vertebræ are in an exceedingly rudimentary condition. In many animals the plate of bone which occupies the base of the skull is reduced to the thinness of paper; and in the lower circles of the mammalian class, as in some of the seals, this state of attenuation is still more perfect;-indeed, in these cases, a thin membranous partition of soft tissues is all that separates the cranial from the pharyngeal cavity, and in the dry skull there is a large aperture where the bodies of the vertebræ should have existed. Such a condition is repeated, also, in the cyclostome fishes, as the myxine or lamprey, and here, if we look at the base of the skull, it will be seen that the bodies of the vertebra are divided so as to enclose a space which is only filled up by a very thin layer of cartilage.

The cyclostome fishes represent an intermediate point between fishes and reptiles, and in them the characters of the organism are exceedingly rudimentary; - and the seal may be said to be typical of the simplest condition of mammal form; and hence we 
may argue that in the corresponding embryonic phases, the skull of the higher animals will be found in a similar state. And that this is the case would appear, moreover, from certain researches which have lately been published in connexion with the development of fishes.

Whatever may be the ultimate conclusion from these facts, of this there can be no doubt, that the "body" may be present or absent in vertebræ which are demonstrably of the same character. The determination of the actual nature of the part is not a simple or easy problem, and at this stage of our inquiry it is impossible to command all the evidence which is needed for the solution; but notwithstanding this difficulty, there is reason to believe that the body of the vertebra is not a central element of the zone to which it belongs; and there is reason, also, to infer, that the supposed centre is a composite formation produced by the coalescence of lateral elements.

And in favour of this inference, collateral arguments may be found in the construction of the cranio-spinal cord of the nervous system, and in the peculiar relation which this cord holds to the bodies of the vertebræ. Whatever may be the ultimate reason of the conformity, it cannot be doubted that between the major centres of the nervous system and the bodies of the vertebrx, there is a very intimate relationship; and inasmuch as the nervous and osseous systems 
agree in that each system is composed of corresponding zones, it may be supposed, without any great or extravagant flight of fancy, that the law of formation of the centre in the one case, may in some measure be explanatory of the law of formation of the centre in the other case. Under any circumstances, it must be admitted that the results of the comparison of the nervous and osseous systems are strangely confirmatory of the inference which has been made as to the nature of the bodies of the vertebræ. What then, it may be asked, is the essential nature of the cerebro-spinal axis? The response is simple and conclusive-namely, that the parts of which it is composed are certainly not simple and central elements, but composite formations produced by the more or less perfect coalescence of lateral ganglia of the primary nervous rings. In this case, then, we have a pseudo-central axis, corresponding in position to the bony axis formed by the bodies of the vertebræ. In this case the nature of the axis is clear and unmistakable; and that the history may be applied to the elucidation of the obscure and doubtful history of the bony column, may be argued from the apparent parallelism of the two. It is in the trunk, indeed, where the bodies of the vertebræ are most developed, and in the atlas and cranial region where these parts are deficient or altogether wanting; and so it is with the axis of the cranio-spinal ganglia: thus, in the region of the trunk, where the bodies of 
the vertebræ are most developed, the lateral nervous ganglia are very intimately connected in commissural union, and the central axis is most perfect; and in the atlas and cranial region, where the bodies of the vertebræ are deficient or wanting, there the lateral ganglionic enlargements diverge into the cruri cerebri, and by this separation destroy the existence of the central axis.

The heart, again, stands in intimate relation to the cerebro-spinal ganglia of the nervous system, and to the bodies of the vertebræ; and of this organ it may be observed, that it is a composite structure formed by the coalescence of lateral portions, and not a central and single structure. Like the cerebro-spinal centres, indeed, the heart is formed by the development of ganglia-like centres in a primitive vascular ring or zone; and the mind of the philosopher will not fail to perceive the relation between the double heart and the double ganglia of the cerebro-spinal system, and in this analogy to find additional confirmation of the inference which has been drawn as to the nature of the body of the vertebra.

The consideration of these collateral facts furnishes not only reason against the belief in the necessary centrality of the body oi the vertebra, but it suggests a definitive idea as to the real nature of this part-it suggests, indeed, that the osseous chain of the bodies of the vertebræ is not a single and central 
axis, but a composite axis produced by the union of lateral chains of ganglia-like osseous centres, the coalescence being effected by earthy commissural filaments, analogous, in essential particulars, to the filaments which connect the ganglial elements of the nervous axis.

Again: The idea of the non-centrality of the body of the vertebra gains in probability, and the previous considerations receive additional confirmation, if we attempt to deduce the nature of the part from the office which it is destined to fulfil. The principal office is not peculiar and special. In one point of view, indeed, the "body" is only one of several joints which serve in the connexion of vertebræ; and as it may be expected that the performance of similar duties implies the presence of analogous parts, we may well believe that the comparison of the vertebral junctures each with the other will issue in a better knowledge of the real nature of all. For this reason, then, we may hope (by the comparison with organs whose office is in some measure analogous) to obtain a clearer insight into our problem; and to this examination we therefore proceed.

In the vertebre of the cranial region generally, and of the thoracic region in chelonians, as in the anelle of the cranial and thoracic regions of articulate animals, the vertebra are joined together by the complete apposition of the entire edge; but in the 
trunks of vertebrate animals generally, the office of comnexion is confined to certain points of the zones, which points, in number and position, vary in different animals.

On surveying the many varieties of the vertebrate skeleton, there is found to be a tendency to the formation of surfaces or processes, by which contiguous vertebræ are connected together, at those parts where limbs and appendages spring from these vertebræ. The skeleton of the fish is primarily suggestive of this opinion. Thus: at the parts where the sternal and dorsal fins are given off (provided these fins be well developed) there is a chain of osseous bodies formed by the development and articulation with each other of the bases of the fin-rays, - and thus there is, as it were, an additional spinal column in the median line above and below the true spinal column. In animals higher in the scale of creation than the fish, the tendency to the development of limbs from the median regions disappears in a great measure; but still, in the articulations of the sternum and the imbrications of the bases of certain spinal processes elsewhere, we may find traces of organization confirmatory of a similar disposition. In the chelonians, moreover, the bases of the posterior spinal processes in the region of the carapace are developed into perfect articular surfaces, by the union of which a pseudo-spinal column of a rudimentary character is formed behind the nervous 
cord and the true bodies of the vertebræ, which bodies in this case exist, as has been already mentioned, merely as broad belts arching over the nervous centres.

In addition to the last-mentioned processes, a double chain of lateral connecting surfaces is developed in the majority of vertebrate animals behind the bodies of the vertebræ; namely, the oblique or articular processes. It may be argued also that these processes, equally with the chains of bones in connexion with the sternal and dorsal fins of the fish, are in relation to limbs, or organs. At any rate, in connexion with them are osseous projections which tend in an outward direction,_-processes which, though more rudimentary in point of development than other processes in connexion with the same vertebræ, are yet in many cases, (especially in marsupial animals and birds, ) developed in such a manner as to leave no doubt as to their positive existence. In these animals, indeed, the outwardly projecting portions of the oblique processes are developed to such a degree, and the resemblance to the spinal and transverse processes in the same animals is so marked, that it seems as possible to doubt that the spine of a vegetable is the rudiment of a branch, or the ridge of the sternum and the spinal processes of the vertebre in the bird the rudimentary analogues of the limbs developed in these regions in the fish, as to doubt that the process in question is the rudiment of a limb or organ. There are, it is true, no instances 
in vertebrate animals of the perfect development of the limb in this position, but the possibility of such an event is realized in an inferior department of nature in the wings of insects-organs which in position perfectly correspond to this region of the vertebral zone.

Of the several means of connexion between contiguous vertebræ, it may thus be argued that four are connected with limbs or organs: and it becomes a question, therefore, whether the last and most important means of union-namely, the "body," is in like manner connected with limbs or organs. The result of the examination is favourable to such an opinion. Such a connexion is possible,-because there yet remain two important processes of the vertebrate zone-the transverse processes. Such a connexion is probable,-because these transverse processes, and the lateral limbs with which they are connected, are in immediate relation to the bodies of the vertebræ. And if in a former instance collateral arguments in favour of the non-centrality of the bodies of the vertebræ might be obtained from the arrangement of certain nervous and vascular centres, so also, in this instance, similar arguments from the same sources may be obtained in favour of the elements of the bodies of the vertebræ being in connexion with the lateral limbs. Thus: if we look at the distribution of the nerves of the spinal ganglia which correspond 
to the bodies of the vertebra, and of the vessels from the heart, it will be found that these nerves and vessels are mainly distributed to the lateral limbs: and as from this distribution of nerves and vessels it may be argued that the ganglia and heart hold an especial relation to these limbs, so, also-on the grounds already set forth-it may be inferred that the chain of vertebral bodies is bound up in the same alliance.

In connecting the body of the vertebra by this mode of reasoning with certain lateral limbs, additional ground is found for the belief in the doublenature of the part: and, moreover, our knowledge becomes definitive, in that it may be supposed, with a comparative show of reason, that the quasi-centre is formed by the coalescence of articular surfaces in connexion with the transver'se processes and lateral limbs, analogous in their nature to the oblique surfaces of the laminæ of the vertebræ, and to the chains of articular bones in connexion with the bases of the rays of the median limbs of fishes.

It may be argued from these facts that the "bodies" are not primary central elements of the vertebral zone - primary central elements in the strict sense of the word: it may be argued, also, that the plan of the osseous system of the vertebra is a ring or zone, at certain points of which in the progress of development there is a tendency to the production of organs, and not a system of arches arrayed around a central fixed 
and solid axis. As yet, however, we are alone able to conjecture, for to the demonstration we are dependent upon considerations which remain to be disclosed hereafter: in this case, indeed, as in almost every question in nature, there is such an intricate concatenation of the phenomena that we may not understand any single secret until we have unravelled the whole mystery.

The probable determination of the nature of the body of the vertebra, even though this be partially and unsatisfactorily accomplished, is, however, of infinite moment; for by it we are enabled to cope successfully with the difficulties that remain behind. It is, as it were, the half-untying of the gordian knot, by the discovery of the manner in which the ends of the cord are hidden. Without further delay, then, we address ourselves to the completion of our task: and first of all we shall strive to show the essential unity of the vertebrate and anellose zones, "both in the separate parts, and as a whole; and then we shall proceed to the final problem, and attempt to prove that the archetypal plan is absolutely the same in plant and animal.

Bones and vessels and nerves are bound up in mysterious communion, and their harmonious reconciliation in a common purpose may be presumed to 
indicate the probability of a common law of formation. The nervous system may be regarded as a series of rings, in which, at certain points, ganglia are developed; the circulatory system as a series of zones or rings, in which at certain points hearts are developed; the osseous system, also-if it is possible to resolve the central body of the vertebra into lateral elements, and to connect these elements with the vertebral ring, in the same manner that the oblique processes, and the infero- and supero-spinal processes are connectedas a system of rings in which at certain points there are tendencics to bony enlargements. The primary law of formation in these systems, therefore, would appear to be the same: the osseous ring harmonizes with the vascular and the nervous rings; and osscous centres correspond to the hearts and ganglia. Everywhere is harmony and relation: the law of atrophy or of increase is the same in each system, and even the mode of disposition is the same; for ring is enclosed within ring, and osseous centres, and hearts, and ganglia are in direct and immediate relation.

It has been seen that the trunk of an animal is related to an organ in the same manner that the stem of a tree is related to a leaf,-and as the organ is the simpler product of the archetype, it is natural to expect in it a more intelligible revelation of the law of the several component parts of the more perfect forms of the organic element. At this point, then, we 
revert to the eye of the bird, for in this organ may be found the proof that the osseous system conforms to the law of the nervous and vascular systems, and also an archetype by means of which we are enabled to penetrate into the secret of nature so as to see an arrangement of the component parts of the organic element antecedent to that arrangement in zones or rings of which we have spoken. In the first place, the nervous and vascular, and muscular and osseous coats of the eye of the bird exist in the form of broad concentric rings or zones; and in the osseous element, therefore, we have a condition, altogether without any analogue to the body of the vertebra,as simple as, and of a nature common to, the anella of the articulate animal:-we have, indeed, the very condition which we may deduce hypothetically from the considerations which have gone before. In the second place: the condition of the coats of the eye of the bird reveals a mode of arrangement antecedent to that condition of rings or zones which is assumed in the progress of subsequent development; and we are enabled to see that this primordial arrangement is not a ring or zone, but a layer or lamina of a hollow sphere or cell-of which no better ideal representation can be conceived than that which occurs in the eye itself. A primary condition of the osseous system may thus be supposed to be a lamina of a hollow sphere, like a sclerotica, perfect in every part, and fully calcified,- 
of the nervous system, a lamina like the retina,_of the vascular and muscular systems, layers of vessels and fibres equally uniform with the nervous and osseous coat, and altogether destitute of hearts or muscular masses.

The distinctive parts in the organic element of the animal are arranged in such a manner in the eye of the bird, that, when interpreted by the facts which have gone before-it is scarcely possible to doubt the existence of a common law of formation in these parts. The remaining shadows of doubt, however, may be dispelled from the mind if we continue to ponder awhile upon certain trains of thought which originate in the present argument. Thus: proceeding from the eye as a centre we may readily discover certain forms in which the several constituent parts of the organic element may be seen to blend and intermingle together in a common whole. In an uninterrupted series of mutations, indeed, we may follow the eye-type till it blends in the sensory papilla, where a nervous vesicle is still enclosed in, but not distinct from, the protective sac; and hence we may go onwards to the ordinary cell, in which all the distinctive layers are yet undeveloped; - and thus we may conjecture the possibility of the nervous and vascular and mobile and osseous systems being evolved in every cell, in such a manner that each cell may be transformed into a perfect organ or organism. We may pass, indeed, 
as it were, beyond the notion that these systems spring into existence as rings, or even as uniform layers of a hollow cell, and we may merge them into constituent possibilities of each cell-not sur-additions, but necessary effects of the act of development at a certain stage of this act.

And that this final absorption of parts into a common and undistinguishable whole, is not a mere chimera of the imagination is actually demonstrable if we weigh the significance of certain facts which constitute the history of abnormal nutrition and development in the organism. In the history of abnormal nutrition, on the one hand, the facts are altogether conclusive as to the absence of absolute properties in any of the simple structures of the organism. From the nutrient plasm effused in the neighbourhood of nerve, nerve is formed; of muscle, muscle; of bone, bone. The history of abnormal nutrition shows, also, that the characters of perfectly formed structures are not absolute; that it is impossible to isolate any one, and say that this is peculiar and special to the properties of life and animation, and that devoted to purposes of a mechanical and menial nature. The higher faculties of life are most plainly revealed in nervous matter, and most latent in cartilage and bone, but there is no impassable line of demarcation between the organs of the higher and lower functions; and thus it is that nerve may become degraded to 
the condition of simple areolar tissue or mere cartilage, when insufficiently nourished or exercised; or, on the other hand, the lowest of all organic textures, the bones or cartilages, when stimulated by an abundant supply of blood, as in inflammatory action, may become endowed with exquisite sensibility. In the history of reproductive development, on the other hand, the germ is seen to be destitute of any absolute properties by which it must of necessity become this or that animal or plant. The germ is a simple cell, and if not fecundated, it is extruded as a simple cell, unaltered and unchanged. The attributes of a higher and definitive life are stamped only in fecundation and gestation. The entire history of the development is confirmatory of the absence of any absolute properties in the germ. Just, indeed, as the special characters of the queen bee are determined by the nature of the food supplied to her in the royal cell, and by other circumstances of an equally extraneous nature, so does the special mode of development of every germ depend upon the nature of the food, and other influences, supplied by the parents during the time that the germ is lodged in the ovary and uterus. The resemblance to parents, and the production of hybrids in animals and plants, are sufficient proofs that the germ is not an absolute entity, but a something, the characters of which are impressed by the accidental combination of circumstances by which it is affected. 
Cells cannot, indeed, be regarded as devoted exclusively to a certain function or office-to a nervous or mobile function, for instance, or to the passive office which devolves on bone. As the possibility of every function and office is mysteriously shut up in the primordial ovule or germ, so also in every cell of the future organism the same universal capacity must be supposed to lie hid. It is only when the conditions of development are constant, that the results-be these results manifested as entire organisms or as mere formative elements-are constant: let the conditions be changed, and the results are changed also. And to conclude: the legitimate inference from these considerations is this-namely, that as the elements of which the several systems of the organism are composed are not absolute and fixed, but, as it were, susceptible of intermingling and blending with each other, so in this fact, when collated with the facts which have gone before, we have a very important argument in favour of the existence of a common and universal law of formation of the osseous, the vascular, the nervous, and the other systems of the organism.

\section{2.}

To destroy the idea that the body of the vertebra is a fixed and central element, is to remove the principal ground of difference between the vertebral and anellose zones, by resolving both into the simple ring. 
at certain parts of which organs may be developed. The differences dependent upon the relative arrangement of the osseous, and muscular, and vascular, and nervous elements of the zones are minor difficulties, to the explanation of which we may arrive if we attend to certain well known varieties of organic form.

The eye of the bird, for example, is a typical form, well calculated to show how the anellose and vertebrate zones may interblend. This organ is calculated to show that the vertebra and anella may correspond with each other not only as a whole, but also in the mode in which their several component elements are disposed. In the eye of the bird, indeed, the characteristic features of the two varieties of zone are jointly exhibited, and in such a manner that it can be seen without any obscurity how the one may pass into the other. The anterior region of the eye may be considered as typical of the anella - the posterior region, of the vertebra. Anteriorly, in the region of the tunica albuginea, the soft tissues external to the sclerotica are altogether atrophied, or else developed in the most rudimentary manner, so that the sclerotica or osseous element is wellnigh external; while, on the other hand, the internal structural elements, as evidenced in the ciliary processes, tend to a higher degree of development. Such, indeed, is the arrangement of tissues in the anterior region of the eye, that if we call to 
remembrance the exposed condition of the sclerotica, and imagine the ciliary processes developed into bundles of true muscle-a possibility sanctioned by the function of these processes--this part of the eye may be supposed to be the analogue of the anellose zone. Posteriorly, the condition of the eyeball is widely changed, and the sclerotica is deeply buried in consequence of the great development of muscle and other soft structures that has taken place on its outer surface; and this part of the eyeball, therefore, is in a condition typical of the vertebrate zone.

It may be understood, without any credulity, that the tendinous tissue of the tunica albuginea may be transformed into muscle; or that the muscular coverings of the posterior part of the eyeball may be atrophied into the condition of tendon,-in like manner it may be understood that the vascular and nervous layers may be the subjects of atrophy or increment, as the case may be-and, therefore, we may learn from the eye, as an experiment prepared by nature, that accordingly as the soft tissues are developed externally to the osseous element, the result will incline either to the anellose or to the vertebrate type-to the former, if the change is towards the minimum; to the latter, if towards the maximum.

The zones of the trunk of the tortoise among vertebrate animals, and of the crab among articulate animals, are forms in which the apparently opposite 
characters of the vertebra and anella are reconciled in a very extraordinary manner. In the thorax of chelonians the soft tissues are alone developed internally, and the osseous layer, by reason of this arrangement, is placed externally: so that the conformation typical of the anella is in this instance met with in the zone of a vertebrate creature. In the carapace of the crab, on the other hand, the calcareous processes which project inwardly, and form a groove for the lodgment of the nervous system, and which in some instances unite in such a manner as to form distinct arches, would seem the rudiments of a spinal column -indeed, between these calcareous arches of the crustacean and the bony belts which replace the bodies of the vertebræ in the carapace of the chelonian, the difference is by no means great.

The type of the zone in many molluscous animals is intermediate between the anella and the vertebra. The natural affinity is nearest to the anella; but it is merely necessary to imagine the thick epidermoid layer of soft tissues which encrusts the calcareous element to be somewhat more developed, as is the case in the common cuttle-fish, and the position of the calcareous or cartilaginous element at once changes from without to within, and the zone becomes very closely allied to the vertebra.

In every vertebrate animal, also, there are zones which are transitional to the characters of anella 
in a degree only less perfect than in the carapace of chelonians. These instances, moreover, occur where we should least expect them, and where the characters of the vertebræ are supposed to be most definitively marked-namely, in the cephalic region. All our prejudices are inimical to this analogy, but the facts upon which it rests-namely, the broad, ring-like vertebræ, articulated by the edges with their fellows; - the tendency to the formation of a simple cavity by the disappearance of the floor of the skull; -and the very rudimentary development of muscle and other soft tissues, externally to the osseous element -are sufficiently conclusive when taken in relation to the context. All these facts, indeed, and especially the one last mentioned, show most distinctly how the vertebra is transformable into the anella.

Without any change of typical conformation, indeed, the anella may be seen to pass by an uninterrupted series of transitional forms into the vertebra, and the latter may be considered simply as the more perfectly developed condition of the former.

\section{3.}

One archetypal idea has been seen to reign in all parts of the plant,-and now that the more urgent difficulties have been surmounted which prevented the full realization of unity, we are able to understand also that all parts of the animal are truly correla- 
tive. At length, then, we arrive at the last and most difficult portion of our task, and we have now to show that there is not one law for this, and another for that, but that one grand principle of unity pervades without any distinction every form of organic nature.

In matter, -in essential form, - and in the primary evidences of life, an absolute analogy may be said to exist between the plant and animal. In both, a perfect conformity as to material elements has been shown by the chemical researches of late years. In both, the sphericity of the germ, and the curved outlines which are conspicuous in every future product of this germ, indicate roundness of form to be an unfuiling characteristic. In both, there is the same cver-teeming faculty of birth and growth.

The difficulties, therefore, which oppose unity, do not exist at the onset, where we have concern with the primary properties of the archetypal element of organic nature; and it remains then that we pass onwards, and inquire where the obstacles originate which we have been taught to consider insuperable.

1. The first step in the life of the plant would seem to be towards the cell. The transformation of the primary germ into a hollow vesicle,- the appearance of the pith-cavity in the tubular stem,- and of the seed-chamber in the fruit-are among the facts 
which argue such a conclusion. In a similar direction, also, would seem to be the first movement that may be detected in the life of the animal; - for in this case every germ tends to become hollow, and every product of the germ (as is evident from the analogies of the visceral region which have been given elsewhere) is the subject of a similar change. The metamorphosis into the cell, therefore, may be said to be a constant passage in the early history of the archetypal element of both plant and animal.

2. In speaking of the unity of animal nature, it has been seen that nerve, and muscle, and vessel, and bone, and other special tissues, appear eventually as layers in the walls of a cell. It has been seen, also, that this change may take place in every cell, just as in the primary germ; and hence we may conclude that the transformation of the walls of the cell into layers of different character, is another step in the life of the animal.

It must be remembered, however, that these layers are not constant and absolute, and that the highest and most characteristic are capable of blending in complete and amorphous union with the simplest and most rudimentary. In the sac of the simple polype, for example, or in the coats of the ovum, there is that reduction to unity which is conclusive as to this fact.

In the flower, which in form may be considered as 
the analogue of the polype, the structures are scarcely less perfect than in the plant-animal;-and as the irritability in the one case is the shadow of muscular and nervous attributes, so, in the other case, we may argue that the analogous property is of a similar signification. In many fruits, also, there is a distinct separation into layers, and in the stone we have that which may be considered as the direct analogue of the shell of the molluscous animals. It cannot be doubted, indeed, that there is a disposition to resolve into layers in the cell-element of the plant; and in these facts, moreover, there is sufficient reason to suppose that these layers may be directly analogous to the rudimentary structures of the animal with which they appear to correspond.

3. Another step in the life of the animal would seem to consist in the transformation of the laminated or laminable cell into a zone.

The spheroidal body of the sea-urchin is a closed sac until the formation of the openings in comnexion with the alimentary system. In the more perfect forms, these apertures are placed directly opposite to each other, and it is thus that the simple cell-like animal may be said to be converted into a true ring or zone. The visceral region of the higher animal is at first also a closed sac, and the communication with the interior is made secondarily by means of two apertures placed oppositely to each other. The sim- 
plicity of the process is much obscured by the changes of form which the animal undergoes subsequently; but in the midst of every disguisement, we may discern the essential analogy to the process witnessed in the sea-urchin. On the other hand, if we descend to animals which occupy a lower rank in the radiate province of nature, it is found that the visceral region is pierced by a solitary opening: but we must not omit to observe that, in the star-fish, which is the first link in the descending series from the point where we commence-the traces of a second opening are visible.

In these plant-animals, therefore, the zone is imperfectly formed; but in the sea-urchin, where the animal characters may be said to become strongly marked for the first time-and in all animals higher in the scale of being, it may be stated, as a general rule, that the visceral region is opened by two distinct and opposite apertures:- and hence, taking the sea-urchin as the typical form in which the general change is simplified in the extremest degree, we may conclude, that the essential part of the process is the transformation of a closed cell into a zone, by the formation of apertures at opposite points.

The globe of the eye, again, exhibits the cell in the act of zonular metamorphosis, with the cavity wellnigh opened anteriorly at the pupil, and exhibiting also the traces of the other aperture in the partial 
deficiency of the vascular and nervous coats at the point called by anatomists the foramen of Sœmmering. This organ, indeed, is in the rudimentary condition typified by the star-fish and polype, where a single opening alone exists, and where, consequently, we have not reached the more perfect state seen in the sea-urchin.

It would appear, also, that the formation of the zone is the cause of that detachment of portions from the parent which is the essence of the process of reproduction, whether this process be seen in the separation of a germ from the ovary, or in the division of the body of the Nerëis. During the change in question, there will be an abstraction of matter from the regions where the openings are to be formed-for there is ever at work a "law of compensation," by virtue of which one part must be atrophied if another be unduly developed: and as one of the results of this abstraction, we may suppose that the parts adherent to the parent will be gradually removed, until eventually every attachment is loosened, and the part is free. It is thus, indeed, that we imagine the constrictions in the body of the Nerëis to be formed by the wants of those portions which are in process of transformation into the offspring,-or the singular constrictions whence the insect has its name, by the growth of the cephalic and thoracic and abdominal regions of the animal. 
In the plant, also, the operation of a similar change may be detected, but here it does not advance to the same degree of perfection. As in the lower radiate animals, indeed, the cell is opened by a single aperture, and consequently the zone cannot be said to be completed. Of the existence of the single opening, however, there can be no doubt, for whether we look at the sac of the leaf as seen in the utricle of the pitcher-plant, or to the cup of the flower, or to the chamber of the fruit, there is the same evidence of the formation of an opening at the point opposed to that by which the part is attached to the parent-plant. It is the same also in the buds of the zoophyte, and hence we may conclude, that the process of the formation of these openings is essentially analogous to that by which the mouth of the polype is unlocked. On the other hand, the tendency to the completion of the zone may be traced in the detachment of the fruit or seed from the parent,-_for as, in the animal, so in this case we may argue that the efficient cause of this change is the removal of matter from the connecting part; - and as this part is directly opposed to the opening which actually exists, we may conclude that the same tendencies are present in the cell of the plant as in the animal, and that the completion of the zone is the event to which the act of development progresses.

4. If we follow the progressive evolution of the 
animal frame, the next step appears to consist ill a partial or complete division of the zone into segments. Just as in the former case, the formation of the apertures in the hollow sphere were caused, or seemed to be caused, by the increase of the zone at the expense of these parts, so in this case the division of the zone into segments would appear to be occasioned by the development of certain parts of this zone at the expense of others. The effects of this segmentation are manifested in many different ways. In the nervous layer of the vertebrate and anellose zones, for example, we witness the formation of ganglia; in the mobile layer, of muscular masses; in the vascular layer, of cardiac centres; in the osseous layer, of bony nodules; and so on of the remaining layers. The ambulacral lines of the star-fish or sea-urchin are rudimental traces of the division of the zone into segments. The tentacles of the polype or of the cephalopod are formed in part by the division of the edge of the zone into segments, and in part by the subsequent growth of these parts, just as the petals of the flower are formed, by a mixed process of growth and division, from the original closed sac of the corolla. And, finally, the complete separation of the zone into distinct parts may be scen in those polypes which multiply by division-or by an extension, as it were, of the same process which in its commencement is seen in the cutting out of the tentacles. The accumulation of 
matter at certain points, and the compensative abstraction from others, appears to be the efficient cause in all these changes, and the formation of a ganglion may be supposed to be brought about by the operation of the law which cuts up the zone of the polype into distinct portions:- and it may be remarked, also, that segmentation differs from the process last under con sideration, and which may be called zonulation, merely in the direction of the lines of separation.

A division of the zone into segments would also seem to be the succeeding movement in the life of the plant. The meridional lines on the surface of the echinocactus may be considered as traces of the division of the plant into segments. The separation of the component parts of the bud into leaves, or petals, or stamens, is an undoubted segmentation; and the dehiscence of the fruit into carpels is the more perfect evidence of the same change.

The metamorphosis of the zone into segments may therefore be considered as a phenomenon common to plant and animal.

5. If now we turn once more to the plant, we trace, without any difficulty, the movements which succeed to the resolution of the zone into segments.

On making a horizontal section of a succulent Cactacean, for example, we find in the midst of the softer tissues a woody zone formed by the interlacement of certain fibres which proceed in all directions from 
centres that correspond to the rudimentary buds on the exterior. This woody zone, moreover, is strengthened by the growth or addition of new fibres, as the plant increases in age; and hence-be the change what it may-it must be of an opposite nature to that which causes the splitting up of the plant into distinct segments.

Another view of the same plant reveals to our notice other facts by which_-in part, at least_we are able to interpret the former. On separating a joint of the Indian fig, for example, it is found that the eyes on the surface may be developed-some as stems, and others as roots. It would thus appear that the centres which are seen in relation with the woody zone in the interior of the plant are intimately connected with true buds, and hence it may be inferred that the fibres of this zone hold a root-like relation to these buds-as, indeed, was pointed out long ago by Dupetit Thouars. To connect these centres with buds is to gain, moreover, a definite idea as to the mode of their development - for as the bud is analogous to the seed, so we may suppose that the perfect development of the bud will be as a system of processes radiating from a centre-a miniature repetition, indeed, of the branching systems of the root and stem.

On examining the sections of many succulent fruits, we find a delicate zone of woody fibres as in the pear, or a well formed layer like the stone of the peath, _-and 
there is no difficulty in relating these formations to the woody zone of the cactus: and frequently, also, the surface is covered with eminences which remind us of the rudimentary buds of which we have spoken. In addition to these phenomena, however, we notice the growth of ovules into the seed-chamber. At times, these ovules may spring immediately from the walls of the cavity, and at times they are supported on peduncles, which have the name of dissepiments, and which hold the same relation to them that the branches hold to the buds. There is nothing remarkable in the ovule,but the dissepiments differ very considerably in different fruits. Occasionally these processes are scarcely discernible, or they exist as mere ridges; at other times they form wide fan-like screens; and not unfrequently those growing from opposite sides contract adhesions with each other, and form what is called a central placenta in the midst of the seed-chamber of the fruit.

These are the principal phenomena which demand attention, and from them we may conclude, that two orders of processes radiate from the segment;-for it may be supposed that the bud centres of the zone of the plant are as much the products of segmentation as are the distinct petals or stamens which enter into the formation of the flower. In the one order may be classified the free organs which are repetitions of the parent_-such as buds or ovules-and in the other all 
kinds of commissural organs, whether these be roots or dissepiments, or bundles interweaving with each other in the solid textures of the plant.

If now we turn to the animal world, we find a similar law of growth in the segments into which the organic zone has been resolved.

In articulate animals, there is abundant evidence that the zones of the body are strengthened and con. nected by commissural growths. The ganglia of the nervous rings become united with each other, both in a transverse and longitudinal direction. The vascular rings may themselves be particularly developed, as in the beaded circular heart of the common worm, or they may unite and form the dorsal vessel of the higher articulate animals-and these changes would seem to involve growth in the directions seen in the nervous system. In the solid layer of the anella, also, we find evidence of union contracted laterally between the component segments of a ring, and longitudinally between different rings, when we compare the thorax of the insect with the corresponding region in the myriapod. Analogous phenomena might be indicated in every department of nature, but these are sufficient to show the operation of a law of growth in the segments of the animal, similar to that which has been seen in the plant.

In the animal, also, there is abundant evidence of the inward and outward extensions of the segments. 
The facts, moreover, which concern this mode of growth, are of especial interest, as, by their means, we may hope to complete the evidence of organic unity, and to show that it is as impossible to consider the plant absolutely distinguished from the animal by the possession of the root, as to suppose the animal necessarily separated from the plant by its visceral system. Let us diligently attend, then, to the topics which remain to be discussed.

The essential phenomena in connexion with the growth of the segments from the outer surface of the zone are most clearly revealed in the radiate province of nature. In the star-fish, indeed, the arms are distinctly seen to be the effects of an increase in this direction, for the parts in which these organs originate are enclosed between the ambulacral lines that indicate the segmentation of the animal. And by passing from hence as a centre, it is possible, on the one hand, to connect by a continued series of links these arms, with the limbs and instruments of sense of the higher animals; and, on the other hand, to pass downwards, through the branches of the Pentacrinus, and the tentacles of the polype of the common zoophyte to the organs of the plant; and hence we may conclude, that all manner of external processes in plants and animals, spring without distinction from the segments, and are the signs and evidences of this segmentation. If it were not possible, therefore, to discover a 
direct analogue of the root in the animal, we might argue the possible existence of such an organ, from the manner in which we may connect, by means of the zoophyte tentacles, the outer processes of the plant and animal. But we are not left in doubt, for even in the animal the root is not without its true representative. In the molluse, for example, the foot, which, as its name implies, is a true limb, may either bury itself in the earth, or be still more completely fettered by the fibres of the byssus. And, again, in the mammalian embryo, there are certain processes at first undistinguishable from the rudiments of the future limbs, which expand like a root, and eventually become attached to the inner surface of the uterusindeed, the placental apparatus is a root in function, for by it the nutriment is conveyed to the nascent embryo.

Many different processes pass inwardly from the segments into the cavity of the zone, and it concerns us especially that we acquire a clear idea concerning their nature. In the animal, as in the plant, they may be divided into two classes-namely, those which effect the subdivision of the cavity, and those which exist as free organs.

In respect to the nature of the processes which belong to the first class, there is abundant evidence in certain facts with which we are already acquainted. Commissures are found to connect different ganglia of 
the nervous system, so as to form a central axis in the interior of the vertebral or anellose zones. The heart, also, is formed by the union of certain vascular centres which were once apart. In the osseous system, again, if we are to credit the conclusions which have already been drawn, the chain of vertebral "bodies" is formed by a similar coalescence.

In these cases, we witness effects which are similar to those which arise from the union of the dissepiments in the fruit;--and if we lose sight of special structures, and simply attend to the plan upon which they are disposed, it is evident that the act of formation of the cerebro-spinal cord of the nervous system, and of the heart, and of the chain of the vertebral bodies, may be considered as so many varied aspects of the process witnessed in the formation of the "central placenta" of the fruit. And when we consider the analogous functions which are performed by the osseous system of the animal, and by the woody system of the plant, and how the special structures of the two seem to interblend in the substance which gives form and strength to the ancllose zones of the insect, it is no extravagant conclusion to suppose, after so many proofs of unity, that the vertebral column, and the "central placenta" are not indirectly analogous to each other.

The nature of the processes which belong to the second class, or those which constitute the free organs of the interior of the zone, may be determined without 
any difficulty. It must be remembered, indeed, that the interior of the zone is equivalent to what we mean by visceral cavity: and hence it is evident that the contents from whence this cavity has its name, may be considered as the effect of a certain growth in an inward direction. The problem under consideration, therefore, concerns the nature of the visceral organs of the animal; and this is of no great difficulty if we persevere in the plan of investigation which we have adhered to elsewhere.

As we descend in the scale of being, the alimentary system is found to undergo a gradual simplification, until we arrive at the star-fish. Here the mystery is in part solved, and in the branching half-glandular and half-digestive processes which are lodged within the arms, we find how the glands are but miniatures of the stomach. The entire alimentary system of this animal is indeed but a highly composite gland, for there is but a single aperture which serves equally for the ingress and egress of the matters employed as food. Again, in the crab or lobster, we often find on one side an ovary, and on the other side the same element developed into the tubular organ of the opposite sex. And thus by a process of gradual degradation we may ally the alimentary apparatus to the simplest of glands.

The actual nature of the alimentary system may be further understood if we consider a remarkahle fact 
in the history of the Holothuria. When this animal is irritated, it frequently happens that the entire contents of the visceral cavity are expelled by the violent contraction which takes place, and the body is left like an empty purse; and yet no fatal injury is experienced, and the whole of what is lost is replaced with as little difficulty, and apparently in the same manner, as the new germ in the ovary. In the lower forms of polype, again, the alimentary system is a mere cup; and the immediate relation of this to the outer case of the creature is evident in the fact that the animal may be turned inside out withos any detriment to its healthy functions. It would thus appear that the alimentary system may be considered in one point of view as a polype growing from the walls of the containing cavity - or as a magnified evoIution of one of the simple ciliate cells which are found upon the membranes with which this cavity is lined: and hence it loses all absolute and specific character, and becomes merely a modification of the common archetypal element.

The abstract definition of the abdominal visceral cavity and the alimentary apparatus may therefore be said to be a simple polype containing a creature like itself-a glandular follicle, as it were. And if this be the case, there is no difficulty in showing the existence of a true visceral cavity and contents in the plant. In the seed-chamber of the fruit, indeed, there 
are organs which may be considered as actual representatives of the parts which originate and foster the germ of the animal; and if the ovary is a visceral organ, so also-if we are to be in any way guided by function, structure, and products-the "placenta" of the fruit is a visceral organ. In the fruit no alimentary system is developed, but this is the case also in the simpler forms of animal life. In the polype, however, the presence of the ovary is deemed a sufficient earnest of the possibility of the development of other visceral appendages elsewhere; and as this is the case here, so in the fruit it is legitimate to infer that the presence of the "placenta" argues the existence of the same abstract possibility.

It is sufficient to our purpose, however, that the contents of the fruit may be allied to the ovary of the animal, for by virtue of this analogy the "placenta" is shown to be a true visceral organ, and the seedchamber of the fruit the representative of the pelvic or abdominal cavities of the animal.

It is interesting to observe, also, that the rudiments of the organs which are especially distinctive of the thoracic region of the higher animals may be found in the plant. Thus in the laticiferous ressels are found the rudiments of the capillaries; -in the focal movements of the nutrient fluid, or latex, contained within these vessels, are the first faint riplples of the waves which agitate the blood of animals provided 
with a heart; -and in the spiral vessels of the plant are the almost exact representatives of the tracheal tubes which intersect the body in the majority of the insect tribes, or which, in a more developed form, are confined to the lungs of the mammal.

And, lastly, even in the cranial region of the visceral cavity there is an absence of that which is absolutely distinctive. This region in many of the lower animals is continuous with the general cavity. The nervous system, moreover, has been found to disappear in the irritable tissues of the polype; and hence we may suppose it to be latent also in the irritable tissues of the plant-and in this manner we may argue that the ganglion is only one mode of the evolution of a common archetype. And here, as if we should not lack a final proof of the possibility of the development of a ganglion in a plant, we find that mysterious and convoluted appearance of the seed of the walnut, which is, as it were, so strange a foreshadowing of the brain.

It would thus appear that the several visceral ap. pendages, and the cavities which contain them, are not absolutely distinctive of the animal, inasmuch as their rudiments may be traced in the plant:-and thus the last distinction is broken down which opposed the perfect analogy of organic forms.

In conclusion, it may be said that a single archetypal idea pervades every living thing, and that the animal and plant_both in the whole and in the part_- 
are embodiments of the same primary law. As the tree is formed by the association of bud-germs, which are essentially the same in nature, so, also, the animal is composed of bud-like parts, correlative in themselves, and joined in indissoluble unity with the archetypal element of the plant.

\section{OF UNITY IN THE FORMS OF ORGANIC AND INORGANIC NATURE.}

In respect to form, and structure, and function, or, in other words, in every property that is deemed essential, inorganic substances are said to be altogether different from bodies endowed with life. They are bounded, it is believed, by angles and plane surfaces in contradistinction to roundness, - they are solid and homogeneous, and, if composed of parts, these are independent, and not in any way subservient to a common purpose,-and last of all, they are passive, and altogether devoid of life and activity.

In reality, however, no such line of demarcation exists between the forms of organic and inorganic nature as that which is here assumed, and any definition of either is maimed and imperfect, which does not recognise the common unity:-indeed, if we do not persist in contrasting that which is highest with the lowest in degree, while, at the same time, we waywardly reject as ummeaning anomalies the inter- 
mediate links which conjoin the two, it is no difficult task to trace a common brotherhood in all bodies, of whatever nature. After the demonstration of unity in the things of life, the solution of this problem is indeed short and simple; and as we examine into it, all distinctions as to outward shape, and internal structure, and function, rapidly disappear-and finally, when divested of the arbitrary disguises of our own imagination, the same archetype is revealed in inorganic substances which animates the form of every living creature.

In place of the angularity, which is assumed to be constant, roundness is a common phenomenon in inorganic substances. Diamonds, for example, have convex surfaces, and at times these gems differ but slightly from perfect spheres. Curvatures are constant in the grains of hail, and in the plates of hoar-frost. Oolite and pea-stone are composed of spherical granules, and " in some masses of decomposing green stone, basalt, and other trap.rocks," as we learn from Mr. Lyell, "the globular appearance is so conspicuous, that the rock has the appearance of cannon-balls." The fragmertary portions of flint-stone, again, occur as rounded nodules. The mammillated or botryoidal masses of certain ores of manganese, copper, silver, and occasionally of calcedony, exhibit curved outlines. And 
lastly, satellites, and planets, and suns, and stars, are inorganic substances, of which the most distinguishing characteristic is the rotundity. Crystals, therefore, singly, and in aggregate masses, are to be found, which differ thus essentially from the terms of the definition, and these, together with the immense orbs of space, are sufficient to prove that the assumption of angularity as the constant property of inorganic substances is altogether erroneous.

On the other hand, it may be shown, that roundness may not be peculiar to organic matter, as organic matter, and, in this manner, perhaps, the fallacy of distinction between the two great orders of bodies, in so far as form is concerned, may be most satisfactorily exposed. Of the substances mentioned, the crystals of which are curved, it may be observed, that some are important ingredients in organization. Carbon, the matter of which the diamond is composed, is a principal element in the constitution of living fabrics. Water, in itself, or in its separate principles, is not less indispensable: and lime, and silex, and iron, are all necessary for the same purposes. It cannot, therefore, but be regarded as a very significant fact, that these substances, when in an unorganized state, present crystalline forms which are partly devoid of angles. It may be observed, also, that the parts of the organism in which curved outlines are most con- 
spicuous, are those which, if not fluid, are soft, or in a condition intermediate, as it were, between fluidness and solidity. Now this shape is equally the property of inorganic matter when in such a state. The drops of dew and rain are rounded, and so are the drops of quicksilver, and of melted metals and earths. Roundness in these cases is the consequence of the state, and hence it may with justice be argued, that the form of organic bodies, instead of being special and peculiar, is the natural consequence of the condition in which the material is found. Hence, in the matter itself, and in the condition of this matter, there is a double reason to discard the notion of any speciality in the mere roundness of organic form.

Other and higher shapes, which seem to reflect the flowers and branches of the plant, are also to be found in inorganic nature. The flakes of snow and hoarfrost, for example, are composed of crystals arranged in such a manner as to afford no imperfect resemblance to the disc of the polype or flower. In stalactite pendants are often found the images of fungoid plants; and in the mammoth cave of Kentucky, Dana speaks of alabaster rosettes a foot in diameter, and surrounded with circlets of elegant leaves, and of vines with tendrils and foliaceous organs composed of the same stony substance. The moss-like appearance of the mocha-stone, - the miniature trees of hoar-frost, 
- the branched forms in which native silver and copper are often found, and the like appearances which frequently occur in artificial crystalline masses, as of lead or zinc, are other instances in which the characteristics of vegetation would seem to be shadowed forth in (a so deemed) lifeless matter.

In respect to outward form, therefore, there are many circumstances which seem to justify the admission of inorganic substances into the same category with living things. And as a further argument in favour of this analogy, it may be supposed that the more angular of crystalline forms have their shape determined in part by extraneous, and, as it were, accidental circumstances-even as the cellular elements of organic bodies are often converted into polygonal forms by outward pressure, and in part by an innate disposition of the crystal itself to produce the angles by an act of growth analogous perhaps to that which produces the various processes in the cell. Indeed, however different their respective destinations, the crystal and the cell may be said at times to spring together from the state of solution, for among the host of germs of albuminous matters which are found in the nutrient fluids of the animal, are others absolutely similar in visible properties, but which, from their chemical reactions, are known to be of an earthy nature. Be this as it may, however, the received 
definition as to form is not absolute, and in the facts which have been given, there is reason to suppose that in this respect at least, the boundary between the bodies of organic and inorganic nature may be broken down.

\section{2.}

In internal structure, also, as well as in outward form, the definition of inorganic substances would seem to be arbitrary and untrue. Instead of being solid and homogeneous, crystals frequently resemble cells in the possession of internal chambers. Cavities are well known to exist in many saline crystals. Cavities which frequently contain minute and detached grains, are very common in the spherules of oolite and peastone. In silex, again, the condition is similar; and the well-known flint nodules are hollow egg-like stones, containing a smaller nodule, which is often so loose as to rattle when shaken:indeed, the whole may be well taken as the analogue of the cell and its nucleus.

The wall of these earthy chambers, moreover, is occasionally composed of layers so arranged as to remind us of the laminated coats of the organic cell. In the granules of oolite and pisolite, for example, this arrangement is very perfect, and a polished section has the appearance of a transverse division of the spine 
of the sea-urchin. The laminated structure, also, is seen where no cavity exists, as in the globular masses of resinous trachyte, or pitch-stone porphyry, which are mentioned by Mr. Lyell (on the authority of Mr. Scrope) as occurring in one of the small islands near Terracina, or Gaicta, and which when acted upon by the weather, separate readily into concentric scales like those of a bulbous root. And again, to compare great things with small, a similar arrangement may be said to occur in the several strata which compose the crust of the earth.

The indistinct shadows of true organization would seem to extend, moreover, to that union of fluid and solid which is thought to appertain exclusively to the creatures of life. A liquid, indeed, is contained in the cavities of many crystals, as in quartz and silex, and in numerous saline bodies: and in the earth, which is the most complicated of inorganic structures, fluids are associated with solids in such a manner, as to lead us to suppose that the streams and rivers which flow on its bosom may be traced in one continuous and unbroken current through the open canals of the sponge, and the channels of the plant, into the streams which pass through the reins and arteries of the animal.

Inorganic substances have been supposed devoid of internal structure only because our standard of com- 
parison has been too high. The plant, however, is lower in degree than the animal, and by the same test the inorganic body is lower still: and therefore if there be any direct analogy between them it must be in the highest phases of the one, and the lowest of the other. It is between the rudimental conditions of animal and vegetable structures, which are represented by the mass of simple cells, and the composite crystal, that the comparison is to be instituted, if this is possible: and that it is, and that the analogy up to this point may hold good, we have in evidence the quasi-cellular form of some crystals, and in addition to this, the branching and stellate shapes that mimic much higher products of vegetation.

It would appear, therefore, that in respect to structure as in respect to form, the definition of inorganic substances is false and erroneous,-and hence there is another reason in favour of the unity of visible nature.

\section{3.}

The distinction in function is no more tenable than the rest. Inorganic and organic bodies are said to differ in no less a degree than the absence of that life in the former which animates the latter; but here, also, we have concern with a fallacy born, like the rest, in the comparison of extremes. What is the 
life, it may be asked, of which we speak? It is no absolute attribute of uniform character and unchanging intensity, but ever mutable, it appears now in visions of poetic inspiration, and now in the impassive phenomena of growth, or lower still in the mere resistance to decay and death. The phenomena of life revealed in the brain differ, indeed, so widely from those that are witnessed in the bony structures and in the plant, that we agree to banish from the latter all the intelligence and sensibility which is characteristic of the former.

Infinite degrees, therefore, must be admitted in the idea of life,-and of these, which-we may now askis the one that we may expect to find in inorganic substances? It is evident that our expectations must not be high and extravagant, and that it is not with displays of mind that we have to deal. Already we have seen that the phase of organic structure with which inorganic substances correspond is not higher than the simple mass of cells, which is seen to be devoid of every attribute of life except that of growth. Crystals, moreover, would seem to typify cells degenerated from all high vocations, and reduced to a condition lower even than that of the lime-cell in the shell of the mollusc, or the bone corpuscle. The earth, indeed, may be said to bear a relation to the film of living things which partially incrusts its surface, similar 
to that which exists between the skeleton matter of plant and animal, and each particular creature; or even that it occupies the lower position still of skeleton to these skeletons. If any dependence can be placed upon analogical arguments, therefore, there is reason to suppose that the life of inorganic substances cannot be higher in degree than that of the structures which have been indicated:-and therefore the only definitive signs of vitality which we may expect in them are those of growth-or even something more obscure than this.

With such a view of the nature of life, the evidence which crowds around us warrants a very different conclusion to that which has been drawn in connexion with the inertness and death of inorganic substances. The crystal, for example, is not inactive, inasmuch as it possesses a selective power by which it obtains from the surrounding fluid the means of increase. The power of effecting chemical combinations and decombinations seen in certain metals when in the catalytic state, - the magnetical properties of the loadstone,the mysterious phenomena of electricity and light, and heat and motion, which attend the reciprocal action of masses of inorganic matter, whether this be in the smaller field open to chemical or electrical research, or in the infinite domains of space, where worlds are the antagonizing atoms-all these are phenomena alto- 
gether at variance with the inactivity of inorganic matter. Of the relation of this excitement to life it is the object of the next chapter to treat, and upon this question, therefore, we must pause for the present.

Even now, however, we may form an answer from the facts we already possess, and see that the growth of the crystal and the signs of activity which have been mentioned, are phenomena quite as wonderful as the vitality of the skeleton structures of the animal and plant: and in comparing the one with the other, we may infer that the difference is by no means such as to justify, on the ground of function, the exclusion of inorganic bodies from the category of living things.

And in conclusion, the evidence of unity in the forms of organic and inorganic nature becomes wellnigh absolute, when to these considerations we add the fact, that the matter of which the things of life are formed, occurs also in an unorganized state, and that there is a perpetual and ceaseless flux between the one condition and the other. So intimate, indeed, is this communion, that in life or death it is equally impossible to imagine a distinction. Inseparable, biune, in alternate pulses of being and oblivion, the living creature, like a wave in the ocean, sinks and swells in the matter of the outer world.

Proteus, indeed, is the true emblem of the archetypal law of nature; and the story is something more 
than a mere fiction which tells us, that he who was a man endowed with prophetic attributes, could also, without loss of identity, threaten in a lion or boar, glide in the serpent, wave in the foliage, mingle in the sands and rocks of the beach, melt in the wave, or rush heavenwards in flame and whirlwind. 


\section{CHAPTER II.}

\section{OF UNITY IN FORCE.}

Force is said to be twofold. Unorganized substances possess, as is supposed, a number of agents which together constitute a force peculiar to them; and organized structures are endowed with a distinct and mysterious influence, of which the manifestations are extremely varied, but which are all comprehended in the common term-life. From the results of the last chapter, however, it may be anticipated that this division is more specious than real, and these anticipations are not without foundation, for on careful examination it is found that all differences are related to a common principle of union.

The force associated with unorganized substances presents a simpler problem than the vital power, and with this we commence the inquiries which are designed to lead to the knowledge of unity in every variety of force. 


\section{OF THE FORCE ASSOCIATED WITH UNORGANIZED SUBSTANCES.}

Mr. Grove, in his "Correlation of the Physical Forces," has given us the key by which we are able to discover the nature of initial or abstract force, for he shows "that the various imponderable agencies, or the affections of matter which constitute the main objects of experimental physics, namely-heat, light, electricity, magnetism, chemical affinity, and motion are all correlative, or have reciprocal dependence. That neither, taken abstractedly, can be said to be the essential or proximate cause of the others, but that either may as a force, produce or be convertible into the others: thus heat may mediately or immediately produce electricity, electricity may produce heat-and so on of the rest." "*

The manner in which Mr. Grove establishes his position is as simple as it is philosophical, and it is not easy to conceive any advantageous addition to the arguments which are employed, or clearer and more concise language. Indeed, I consider myself in no small degree fortunate that I am at liberty to employ the words of the "correlation of the physical forces."

The plan of Mr. Grove is to take each physical

* "On the Correlation of Physical Forces," by W. R. Grove, Esq., M.A., F.R.S. 1846.—(p. 8.) 
agent successively, and to show that it may be the cause and the effect of the rest.

"Motion," we are told, "will directly produce heat and electricity, and electricity being produced by it will produce magnetism, a force which is always developed by electrical currents at right angles to the direction of these currents. Light, also, is readily produced by motion, either directly, as when accompanying the heat of friction, or mediately, by electricity resulting from motion, as in the electrical spark, which has all the attributes of common light, its sole difference being, as far as I am aware, in the position of the fixed lines in its spectrum-a position which ever obtains with light emanating from different sources, or even through different media. In the decompositions and compositions which the terminal points proceeding from the conductors of an electrical machine develope when immersed in different chemical media, we get the production of chemical affinity by electricity, of which motion is the initial source. Lastly, motion may again be reproduced by the forces which have emanated from motion; thus, the divergence of the electro-motor, the revolution of the electrical wheel, the deflection of the magnetical needle, are palpable movements reproduced by the intermediate modes of force which have themselves been originated by motion." - (p. 14.)

Taking heat as "our starting point, we shall 
readily find that the other modes of force may be readily produced by it: to take motion first, this is so generally, I think I may say invariably, the immediate effect of heat, that we may almost resolve heat into motion, and view it mechanically as a repulsive force, a force antagonist to attraction, whether of cohesion or gravitation, and tending to move the particles of all bodies, or to separate them from each other."-(p. 14.) "It (heat) will immediately produce electricity, as shown in the beautiful experiments of Seebeck, that when dissimilar metals are made to touch, or are soldered together, and heated at the point of contact, a current of electricity through the metals, having a definite direction, according to the metals employed, which current continues so long as the temperature continues increasing, or rather as long as a moving temperature is gradually pervading the metals, ceases when the temperature is stationary, and flows in a contrary direction with the decrement of temperature. To say that heat will produce light, is in common parlance to assert a fact familiar to every one, but there may be some reason to doubt whether the expression to produce light is correct in this particular application: the relation between heat and light is not analogous to the correlation between these and the other four affections of matter. Heat and light appear to be rather modifications of the same force than distinct forces mutually dependent. 
The morles of action of ordinary heat and light are so similar, both being subject to the same law of reflection, refraction, double refraction, and polarisation, that the difference appears to exist more in the manner in which they affect our senses, than in our mental conception of them. With regard to chemical affinity and magnetism, perhaps the only method in which, in strictness, the force of heat may be said to produce them, is through the medium of electricity, the thermo-electrical current, produced, as before described, by heating dissimilar metals, being capable of deflecting the magnet, of magnetising iron, and exhibiting the other magnetical effects, and also of forming and decomposing chemical compounds, and this in proportion to the progression of heat: this has not, indeed, as yet been found to bear a measurable quantitative relation to the other forces produced by it, because so little of the heat is utilised or converted into electricity, much being dissipated, without change, in the form of heat. Heat, however, directly affects and modifies both the magnet and chemical compounds: the union of certain chemical substances is induced by heat, and cannot take place without it, as for instance, the formation of water by the union of oxygen and hydrogen gases, in others, indeed, in the greater number of cases, the union is facilitated by heat, and in some instances, as in ammonia and its salts, it is weakened or antagonised; in all these cases, however, 
it must be admitted, that the force of heat seems more a determining than a producing influence, yet to be this, it must have an immediate relation with the force whose reaction it determines; thus, although gunpowder touched with an ignited wire subsequently carries on its own combustion or chemical combination, independently of the original source of heat, yet the chemical affinity of the first portion touched, must be exalted by and at the cost of the heat of the wire, for to disturb even an unstable equilibrium, requires a force in direct relation with those which maintain equilibrium."-(p. 21.)

"To commence with ELECTRICITY, as an initiating force, we get motion directly produced by it in various forms; for instance, in the attraction and repulsion of bodies, evidenced by mobile electrometers, such as that of Cuthbertson, when large masses are acted on; the rotation of the fly-wheel, another form of electrical repulsion, and the deflection of the galvanometerneedle, are also modes of palpable visible motion. Electricity directly produces heat, as shown in the ignited wire, the electric spark, the voltaic arc; in the latter the most intense heat with which we are acquainted, so intense, indeed, that it cannot be measured, every sort of matter being dissipated by it. Electricity directly produces light in the same phenomena. It directly produces magnetism in all ferruginous bodies placed at right angles to its line of 
direction, and, indeed, in the substances, of whatever nature, traversed by the electrical current, in a direction at right angles to that of the current; in this case giving us a new character of force-viz., a force acting not in straight lines but in a tangential or rather rectangular direction." "Lastly, electricity directly produces chemical affinity, and by its agency we are enabled to obtain effects of analysis or synthesis, with which ordinary chemistry does not furnish us. Of these effects we have examples in the brilliant discoveries by Davy of the alkaline metals, and in the peculiar crystalline compounds made known by Grosse and Becquerel."-(pp. 26, 27.)

To illustrate the effects of LIGHT as an initiating force, Mr. Grove employs a most elegant experiment. "A prepared daguerrotype plate is enclosed in a box filled with water, having a glass front with a shutter over it. Between the glass and the plate is a gridiron of silver wire; the plate is connected with one extremity of a galvanometer coil, and the gridiron with one extremity of a Brequet's helix; the other extremities of the galvanometer and the helix are connected by a wire, and the needles brought to zero. As soon as a beam of either day-light, or the oxyhydrogen light is, by raising the shutter, permitted to impinge upon the plate, the needles are deflected; thus, light being the initiating force, we get chemical action in the plate, electricity circulating through the wires, mag- 
netism in the coil, heat in the helix, and motion in the needles." - (pp. 27, 28.)

"Magnetism, as was proved by the important ex. periment of Faraday, will produce the other modes of force, but with this peculiarity-that it is itself static: and therefore, to produce a dynamic force, motion must be superadded to it-it is, in fact, directive, not motive, altering the direction of other forces, but not in strictness originating them." "Magnetism, under these conditions, $i$. e., when conjoined with motion, being capable of producing electricity, it follows, from what I have already stated, that it is capable of producing the other modes of force, since electricity is capable of producing them. Thus, we can through the medium of electricity, produce heat and light. Motion it can directly produce, under the above conditions, $i$. e., a magnet being itself moved or raised, will move other ferruginous bodies; these will acquire a static condition of equilibrium, and be again moved when the magnet is moved. By motion, or arrested motion only, could the phenomena of magnetism ever have become known to us. A magnet, however powerful, might rest for ever unnoticed or unknown, unless it were moved near to iron, or iron moved near to it, so as to come within the sphere of its attraction. I have no doubt that magnetism will also directly affect the other forces-heat, light, and chemical affinity, and change their direction or mode 
of action, and will, when in motion, directly produce them; but these remain as facts to be elicited by future experimentalists. There are, indeed, experiments of the older philosophers to show that chemical affinity is directly affected by magnetism." "When steel or iron is being rendered magnetic, and as it progresses from its non-magnetic to its maximum magnetic state, or recedes from its maximum to zero, it exhibits a dynamic force; the molecules are, so far as we can infer, in motion, and while in this state it will produce the other forces; but it may be said, while magnetism is thus progressive, some other force is acting on it, and therefore that it does not initiate: this is true, but the same may be said of all the other forces; they have no commencement that we can trace, - we must ever refer them back to some antecedent force equal in amount to that produced, and therefore the word initiative cannot in strictness apply, but must only be taken as signifying the force selected as the first: this is another reason why the idea of causation is inapplicable to physical production." - (pp. 33 -35$.

Speaking on this subject in another page, Mr. Grove says: "No force can, strictly speaking, be initial, as there must be some anterior force which produced it; we cannot create force or motion, any more than we can create matter. Thus, to take an example, the spark of light is produced by electricity, 
electricity by motion, and motion is produced by something else, say a steam-engine-that is, by heat - this heat is produced by chemical affinity, i.e., the affinity of the carbon of the coal for the oxygen of the air; the carbon and the oxygen have been previously eliminated by actions difficult to trace, but of the preexistence of which we cannot doubt, and in which actions we shall find the conjoint and alternating effects of heat, light, chemical affinity, \&c.: thus tracing any force backwards to its antecedents, we are merged in an infinity of changing forms of force; at some point we lose it, not because it has been created at any definite point, but because it resolves itself into so many contributing forces, that the evidence is lost to our senses, or powers of detection, just as in following it forwards into the effect it produces, it becomes, as I have before stated, so subdivided and dissipated, as to be equally lost to our means of detection."-(pp. 47, 48.)

Chenical Affinity directly "produces motion of definite masses, by the resultant of the molecular changes which it induces: thus, the projectile effects of gunpowder may be cited as familiar instances of motion produced by chemical action."-(p. 37.) Chemical affinity also directly produces electricity; " and the quantity of these currents, as measured by the quantity of matter it acts upon in its different phenomenal effects, is proportionate to the quantity 
of chemical action which generated it; and the intensity or power of overcoming resistance is also proportionate to the intensity of chemical affinity when a single voltaic pile is employed, as to the number of reduplications, when the well-known instrument called the voltaic battery is used."-(p. 38.) "Heat is an immediate product of chemical affinity. I know of no exception to the general proposition, that all bodies in chemically combining produce heat, i.e., if solution be not regarded as chemical action, and even then, when cold results, it is from a physical change, as from the solid to the liquid state, and not from chemical action."-(p. 39.) "Light is also directly produced by chemical action, as in the flash of gunpowder, the burning of phosphorus in oxygen gas, and all rapid combustions: indeed, whenever intense heat is developed, light accompanies it." - (ib.) "Chemical action produces magnetism, whenever it is thrown into a linear direction, as in the phenomenon of electrolysis. I may adduce the gas voltaic battery as presenting a simple instance of the direct production of magnetism by chemical synthesis; oxygen and hydrogen in that combination chemically unite, but instead of combining by intimate molecular admixture, as in the ordinary cases, they act upon water, i.e., combined oxygen and hydrogen placed between them, so as to produce a line of chemical action, and a magnet adjacent to this line of action is deflected, and places itself at 
right angles to the line; what a chain of molecules does here, there is no doubt all the molecules entering into combination would produce in ordinary chemical action, but in such cases the direction of the lines of combination being irregular and confused, there is no general resultant by which the magnet can be affected."-(p. 40.)

In this manner, Mr. Grove establishes his position, and demonstrates, most unquestionably, that the several physical agencies of the inorganic world are truly correlative, and that the bond of union between them is inseparable even in mental conception.

The demonstration of a more intimate connexion than correlation is a task which must remain in abeyance for the present; but even now we may perceive in part why it is that we fail to receive the idea of unity. Objectively, the attention is absorbed by the phenomenon which first presents itself to the senses, and in this manner the mind is shut out from the perception of other and accompanying circumstances, which are not less essential to the constitution of a fact; or subjectively, there is a stultification of that faculty by which we are enabled to recognise the idea of unity in diversity.

The first hindrance to the conception of perfect union in the several physical influences, or that which results from the inobservance of objective phenomena, may be easily illustrated. We regard, for example, 
the light and heat of the natural world as distinct and independent agencies, because we observe them imperfectly, and because we fail to consider them in their connexions. It is impossible, however, to suppose them separate from a certain machinery of matter; and in reality the beams of light and heat in the atmosphere are inseparably associated with the recondite chemistry of life, with the magnetical current, and with the rotatory and translatory movements of the planet,-for all these effects are consequent upon the mutual reaction of the sun and earth. The electrical spark and heat are no more intimately connected with the apparatus concerned in the production of these forces, than are the light and warmth of the sky with sidereal or planetary bodies.

It would appear, moreover, that the several physical agencies of the outer world are associated together in the same manner as in artificial electricity. When free to move, translatory and rotatory movements are connected with bodies electrically excited: a magnetical current also intersects at right angles the line of induction; and chemical affinity and light and heat are other effects of the action. On the other hand, movements of translation and rotation,a magnetical current around the earth at right angles to the direction in which the influence of the sum impinges upon it, certain phenomena of chemistry together with luminous and calorific influences, are 
consequent upon the reaction of the earth and the lunar and solar orbs.

The influences which emanate from the worlds of space are precisely similar to those which accompany electrical induction, and the only difference would seem to be in the magnitude of the field of operation. As to the special nature of the individual agencies, as light or heat, there is indeed evidence of complete identity in either case. The proof of analogy, there. fore, is very strong, and there is every possible reason to suppose that masses of matter affect each other in the same way, whether on the surface of the earth or in space.

The phenomena of electricity may indeed be said to be the natural effects of the inductive reaction of isolated masses of matter, just as the light and heat and chemical affinity associated with the gravitative motion are natural effects of the reaction of the planetary bodies. The electrical apparatus, indeed, may be considered as an artificial miniature of the machinery of space, and the phenomena of force as similar to those which emanate from the earth and cloud in a thunder-storm, or to the quieter and more diffused manifestations of force which take place unceasingly between the heavenly bodies.

In the physical agencies of the natural world, therefore, it is difficult to conceive the idea of distinction and separation, if care is taken to include all the phe- 
nomena which are concerned in the perfect idea, and thus we may understand in part how the faulty observance of nature is a hindrance to the conception of unity in force. It is seen also at the same time that the more comprehensive survey naturally conducts to the idea of union of force, for all the seemingly distinct agencies are related to matter, of which indeed they are symptoms. *

The second hindrance to the conception of unity in the physical agencies, may be supposed to be the faulty operation of that faculty by which the impressions of the senses are concentrated and co-ordinated.

* The imagination is too prone to pry into the future, and to form conjectures as to what will be the result of any doctrine, and it is no easy task to curb this propensity in the present case. To connect, indeed, the phenomena of force associated with the hervenly bodies with those which result from the action of electrical conductors or galvanic plates, is to suppose in these phenomena the possibility of reciprocal interpretation.

The existence and position of the magnetical meridian of the earth, for example, may be in part accounted for, if this planet and the sun and moon affect each other inductively; for this meridian crosses the line of mutual action, just as would be the case if this action were electrical. It may be conjectured, also, that, eventually, the mysterious movements of terrestrial magnetism will be found to be connected with the changes in the relative position of the planetary bodies, which are brought about by the orbital movements.

It may be anticipated, also, that some mysterious and unexplained phenomena in connexion with the tides, will be accounted for when the relative differences of inductive action of the land 
It must be remembered that the organs of sensation are formed from a common archetype, and that the sense in a functional point of view is not so distinct as we are apt to suppose. Sensational impressions, indeed, are often mixed. Persons blind unto advanced life, show that the ideas we usually receive from the eye, are not simply connected with vision, but composite products of sight and touch. The gustatory function of the tongue requires the aid of the nose, and therefore the sense of taste is not simple. And again, when the vision is destroyed, the ordinary tactile nerves often acquire an almost visual delicacy of perceptive power, and the ear takes cognizance of

and water in relation to the sun are properly estimated, for it seems reasonable to suppose that the intensity of this action will change, and the motion and light and heat, which are the expressions of the induction, will vary, when a watery or earthy surface is opposed to the sun.

Certain peculiarities in the orbital movements of the sidereal and planetary bodies, also, may possibly meet with their explanation in the varying degrees of inductive action of which we have spoken. In electrical excitation, indeed, it is found that the velocity of the tangential movement is in proportion to the degree of induction; and if it may be supposed that there will be variations in the force produced, when the earthy or watery hemispheres of the planet are exposed sunwards, so perhaps we may find one cause of the varying velocity in the translatory movements of the earth in different parts of its orbit. Indeed, we may imagine the different degrees of elipticity in various orbits to be determined by the mode of distribution of land and water upon the surfaces of sun, or planet, or comet. 
impressions which do not fall within its normal province.

The impressions of sense, therefore, would not seem to be so absolute as we might imagine, and it is possible to conceive, correlation in place of distinction. At any rate, in one respect, the organs of these senses may be supposed to be correlative.

By a proper generalisation within and without,by a care to appreciate, that is to say, all the objective and subjective elements of the idea, there is even now no lack of evidence in favour of unity in the seemingly diverse agencies, which we call, and which we must continue to call, electricity, magnetism, light, heat, and motion. Practically considered, however, it is immaterial whether the doctrine of perfect union in these agents be admitted, for under any circumstances, it is evident that they are bound inseparably together, and that we can have no concern with one independently of the rest.

\section{OF UNITY IN THE FORCE OF ORGANIC AND} INORGANIC NATURE.

The force of living creatures has a twofold aspect. Agents are present which correspond to those that reign in inorganic nature; and others of mysterious properties that are supposed to be peculiar to the things of life. 


\section{1.}

Organic bodies are undoubtedly the seat and source of influences identical in character with those that are associated with unorganized substances.

The exercise of every function gives rise to the phenomena of heat. The formation of carbonic acid and water, which are the main results of the act of respiration, is attended with the extrication of latent caloric. The temperature becomes elevated in inflammatory action, and sinks as constantly (notwithstanding the absence of any change in the activity of the respiratory function) during a period of fasting. The system is flushed and warm when the brain and nerves are excited, and pallid and cold in seasons of mental depression and nervous inactivity; and heat, therefore, is associated with the most characteristic agent of vitality.

The existence of chemical affinity is implied in the changes which constitute the function of respiration; and the researches of late years have demonstrated the presence of the same power in many processes which were thought to belong exclusively to the province of vitality.

On examining a number of seeds during the act of germination, the electrometer revealed to Pouillet the free development of electricity, and, in many animals, the extrication of this influence is so considerable, 
that they may be said to be armed with mimic thunderbolts.

In certain peculiar states of the atmosphere, many fungoid plants are known to emit light; and the brilliant seaforms that blaze in the eddy made by the paddle of the steam-boat, give evidence of a similar action in the animal world.

Motion, also, is a conspicuous phenomenon in every vital process, and in connexion with the chemical changes, the results are precisely similar to those which would take place under similar circumstances in unorganized substances.

The heat and chemical affinity and electricity and light and motion, associated with the special phenomena of vitality, are demonstrably identical with the agents of like name that are found elsewhere;-and hence, we may conclude, that the force of unorganized substances is present also in living structures.

\section{2.}

1. 'The phenomena of the force which is deemed peculiar to vitality are very numerous and diversified. Beginning with birth, and growth, and nutrition, we pass gradually and imperceptibly into sensibility and motion, into intelligence and will. And lastly, there is in man a something connected with all these signs, and yet distinct-dissatisfaction with the present, and a yearning for the future; - a feeling, akin, perhaps, to 
the restlessness of the imprisoned swallow, when, as the summer draws to a close, she feels the calls of the instinct which has carried her former companions to more genial scenes. The evidence of this undefined impulse is very variable; but it is never absent, and there is always in man an unsatisfied wish which takes him away from himself and the present, though he knows not whither.

This mysterious longing after something unpossessed, - the phenomena of reason, and understanding, and passion, - action, and pain, and pleasure,-growth and birth,- - these are the signs of the second power which reigns in organized structures, and of which we have now to speak.

The nature of the force of vitality is to be sought within, and not without, and man is told by a higher oracle than that of Delphi, that the key to this and many other mysteries, is in the knowledge of himself. What, then, it may be asked, is this living self, of which the varied vital actions are the signs-this strange mixture of inconsistencies, of godlike aspirations and fiendish malignity, of power and helplessness? The reply to this query is altogether beyond the reach of unaided reason, and it is well that man is not without a guide in his darkness and helplessness.

No problem in nature, and least of all that which concerns the mystery of human life, can be solved by 
him who takes his present state as a perfect standard of judgment. In order to true knowledge, it is necessary to compare that which is, with the origin and end of being; for except this be done, the reason is everywhere overwhelmed with contradictions, and the mystery of life becomes more perplexed and inscrutable the more it is examined. Let us endeavour, then, so to search into the stores of knowledge, which are at our command, as to acquire an idea of the real nature of man, for it is in this way alone that we may hope to obtain an insight into the secret essence of vitality.

The pristine condition of man is revealed in the Mosaic record, and the Scripture is by no means obscure, if due carefulness be used in its interpretation. The words which express the act of Deity in the creation of man, are very explicit.

"And God said, let us make man in our own image after our likeness: and let them have dominion over the fish of the sea, and over the fowl of the air, and over the cattle, and over all the earth, and over every creeping thing that creepeth upon the earth. So God created man in his own image, in the image of God created he him; male and female created he them. And God blesserl them, and God said unto them, Be fruitful, and multiply, and replenish the earth, and subdue it: and have dominion over the fish of the sea, and over the fuwl of the air, and over every 
living thing that liveth upon the earth." (Gen. i. $26,27,28$.) At its origin, it is evident, therefore, that humanity differed very materially from the present condition. No mention is made of disease and deatl, and as these are the express penalties of the fall, it appears that man at this time was not feeble and mortal in the sense in which he now is. A difference, also, is seen in the relation of the body to that inward principle which constitutes the identity; and the sense of nakedness which is now experienced, and which supervened upon the fall, did not exist in the time of man's innocence. The dominion over the earth and created forms, of which mention is made, must also have been greater than at present, for at the beginning the ground yielded obedience without labour, no enmity existed between man and the serpent, and no thorns and thistles gave evidence of arrested life in vegetation. Whatever, therefore, may have been the precise attributes of the human image of God when first created, it is evident that a great change has taken place, and that man has been shorn of power and dignity in a plysical as well as in a moral sense.

Turning from the past to the future, the restored condition of man appears still more distant from his present state.

"Verily, verily," says our Saviour, "he that believeth in me, the works that I do he shall do 
also; and greater works than these shall he do; because I go to my Father. And whatsoever ye shall ask in my name, that will I do, that the Father may be glorified in the Son. If ye shall ask anything in my name, I will do it." (John xiv. 1214.) And immediately before his ascension, Christ also says_" And these signs shall follow them that believe; In my name shall they cast out devils; they shall speak with new tongues; They shall take up serpents; and if they drink any deadly thing it shall not harm them; they shall lay hands on the sick, and they shall recover." (Mark xvi. 15, 17, 18.)

Nor are we left in doubt as to the reality of these powers. During the abode of Christ on earth, the disciples had cast out evil spirits, and they continued to exercise the same gift after the ascension. Paul exorcised the demon of divination from the damsel in Thyatira. (Acts xvi. 18.) On the day of Pentecost, the converts had the gift of language; the household of Cornelius magnified God, and spake with new tongues; (Acts X. 46;) and the Corinthian converts spake with tongues and prophesied. (Acts xix. 6.) The immunity from poisons is seen after the shipwreck upon the island of Melita, when Paul, without receiving any hurt, shook off into the fire the viper which had fastened upon his arm. At the Beautiful gate of the temple, Peter and John heal the lameness of the cripple. At Lydda, Peter restores from palsy 
Eneas, who had been bedridden for eight years: and at Joppa the same apostle recals the departed life to the body of Dorcas. The dominion of the disciples at this time is thus seen to be over death as well as disease, and hence it is to be supposed that the faculty of healing, mentioned at the final benediction, is intended to signify also that more comprehensive power which our Saviour communicated at the ordination of the apostles, when he commissioned them not only to heal the sick and cleanse the lepers, but also to raise the dead.

In order to understand the higher nature of man, it is necessary to compare the histories of the unfallen and renewed phases of this nature. Man, we are taught, is raised by the restoration of that which was lost, rather than by the communication of any new attribute; and hence we may expect that the comparison of the one state with the other will be a means of mutual interpretation. And this, indeed, is the case; for although Adam in his purity did not possess the perfected faculties of St. John, yet he had the germs of these faculties, and the difference is one of degree, and not of kind.

The dominion over disease and death is a consequence of redemption, and it would seem also to have been a power belonging to man before the fall. Adam was not mortal in the sense in which we are, for death and disease are the express penalties of disobedience: 
and in so far as his own being is concerned, it is necessary to suppose him supreme over mortality. At this time there is no room for the exercise of such a power over others in subjection to mortality; but this is abstractedly possible, for the first degree of this power, or that which concerns his own individual body, was certainly possessed. In this aspect, therefore, the two natures illustrate each other, and we may suppose that an attribute which was an original cndowment $\_$man has been restored at the redemption.

Immunity from the poison of the serpent and from all deadly things is included, in one sense, in the power over mortality. The exemption from the malice of the serpent, however, may be mentioned, in order to indicate the recovery of the attribute of command over the brute creation, as represented in this typical form, and chief instrument of the fall.

The power over the earth, which is implied in the words of Christ, when he says_ " If ye have faith as a grain of mustard seed, ye shall say unto this mountain, Remove hence to yonder place, and it shall remove; and nothing shall be impossible unto you," (Matt. xxvii. 20,) may be said to be the recovery of that dominion over the earth which was an original endowment of man. Explained by the clearer revelation, the short sentence in the first chapter of Genesis acquires new significance, but the terms are sufficiently full and ample to admit the widest interpretation. 
Compared in this point of view, it would seem that the higher nature of man is exempt from the dominion of the earth and the terrestrial part of himself, and not only so, but that a positive power is exercised over that which now subjects him to bondage.

The speaking with new tongues becomes also a less unintelligible mystery when an interpretation is sought in the early history of mankind. It may be supposed, indeed, that this gift was the natural effect of the removal of the curse which has descended from Babel; and with this view of the mystery two explanations are possible. It may be supposed, that the people of several nations, collected together at the day of Pentecost, were all affected in the same way by the Spirit of Inspiration, and simultaneously relieved from the Babylonic confusion, so as to speak and understand a common language; or else to a limited number of individuals the secret law of the unity and diversity of words may have been communicated, so that the speaker might have at command every dialect of the primary language of man.

And lastly, the dominion over evil spirits imparted by Christ must have been possessed at the creation,for although man fell at the instance of the arch tempter, yet it will be allowed that the power of resistance and victory belonged to him if he had willed their exercise.

The problem of the nature of man may therefore be 
simplified, by merging into one the unfallen and the renewed states, and Adam in the state of purity may be supposed to have had the germs of those high faculties which Christ has regained.

The real nature of man, however, may be still further understood if it be examined in relation to its origin. Man, we are told, was created in the image of God, and that he was transcendantly high and noble may appear in the arguments which have already been usec In this expression, however, there seems to be a deeper significance than that which is usually attached to it, and what this is may perhaps be learnt from the answer of Christ to the Jews when they were about to stone him for asserting his divinity. "Is it not written in your law," says our Saviour, "I said ye are gods?" and then continuing, he adds, "if he called them gods unto whom the word of God came and the Scripture cannot be broken, say ye of him, whom the Father has sanctified and sent into the world, Thou blasphemest; because I said, I am the Son of God."-(John xi. 34, 35, 36.) Now, it is impossible to conceive that Christ would attempt to turn away the anger of his enemies by denying his own Godhead, and therefore this answer would seem to signify most conclusively-for no ignorant reading of the Scripture can be supposed in such a case-the existence of a latent divinity in these men, a godlike nature, exercised not only in acts of judgeship over 
servants and subjects, but capable also of deeds of infinitely greater dignity. Let the nature of man be ever so high, it must be always remembered, however, that it is created; and therefore though the essence be congenerous, there is and must ever be between man and Christ that infinite and impassable distance which exists between the creature and Creator-the finite and infinite.

To assume this high dignity for man is to make more intelligible that nature of which we are attempting to eliminate the characters and properties. Christ being of necessity infinite power, and wisdom, and life, the signs which accompanied his earthly presence and which to us seem wonders and miracles, must be regarded as the natural acts of Godhead. To rebuke and subdue the spirits of evil,- to heal the sick and raise the dead,-to speak with tongues and to read the heart,-are indeed but easy deeds for the transcendant Being who took upon himself this form of humanity. And if the nature of man be such as it would seem to be from these considerations, it is no wonder, so long as it continues unpolluted, that it should possess the attributes which seem to belong to the unfallen and renewed state-indeed, they are the necessary consequence of the nature. The Scripture, indeed, is its own interpreter. Man may be endowed with these powers because he is the image of God, and the exercise of these powers tests the innate divinity. 
The powers would be an inscrutable mystery unless the high nature of man was made known, but the revelation being made, then these become necessary and inseparable.

With man's present state as a standard, the acts of his higher nature are miraculous, but not so when these are compared with the inherent divinity. Undoubtedly Christ, as God, had the power of performing deeds which were altogether beyond the course of nature, and he did perform such, as in the turning of water into wine, or in the stilling of the tempest; but it must be remembered that the greater number of the acts of Christ are not miracles in this sense of the word, but merely revelations of the true law of nature, which is hid behind the veil which shuts out from man in his present state the true knowledge of himself and the universe.

To discover in man a nature such as that of which we have spoken, is to solve in part the mystery of life,- - for if man is the image of Him who is life, and power, and wisdom, it is impossible that he should not be in some degree the possessor of these attributes. With such an origin the wonder is not that man lives, but that he is so dead; - not that he is endowed with power, but that he is so feeble and helpless; - not that he is crowned with wisdom and understanding, but that he is so far sunk in idiotcy and folly. 
If, however, we continue to consider man as he is, in relation to what he was or may be, many mysterious phenomena of vitality which at present perplex us will meet with their explanation. If we consult the sacred oracles, we find that man held his first nature by obedience and recovers it by faith, - and hence we learn that he is free to will and act. We find, also, that by the exercise of faith man may be incorporated into Deity, and even advance into closer and more intimate communion with his Maker; or by the transference of allegiance to the creature he may continually and endlessly depart away from God. In the one case, the result must be ever-increasing life, and power, and wisdom-for Deity is the infinite perfection of these attributes; in the other, the inevitable penalty must be ever-increasing death, and impotence, and folly-for the sole centre is forsaken in which the high faculties of humanity find their support. Man, indeed, is a free being, of capacities boundless either for good or evil; and the phenomena of his life may be seen to be the natural effects of his own will.

Now, it is the distinguishing feature of the present state of human nature, that the thoughts and actions tend to that which is create and finite, and in this tendency we meet with the explanation of many contradictions in vital actions.

The faculties of reason and understanding are continually concerned with objects of sense and time, and 
instead of striving to see the relation of things to each other, and to comprehend the connexion of the whole with the Infinite, they seek after distinction and difference. Doubt, and uncertainty, and error, must be the consequence of such an exercise of the will, and these must be proportionate to the degree in which man allows himself to be enthralled by the creature, whether this be by idolatrous subjection to another person or thing, or by selfish absorption in his own being. It must be so, indeed, for a being like man, who is capable of direct inspiration from Omniscience, cannot find the truth after which he pants in any finite source:-it must be so even according to the light of mere human reason, for if there is unity in form and unity in force, then it must be evident that the study of any single form or force cannot reveal to us that knowledge for which we must appeal to the whole.

Man also will be helpless and uncertain, and encumbered with the multiplicity of his instruments, if he trusts in bread alone, and forgets the higher source of power; and, therefore, feebleness is twin-born with ignorance.

Famine, disease, and death, are also the natural consequences of the misdirection of the will. A being of such capacities as man will suffer want in proportion as he sinks into himself or any creature; and disease and death-which are terms expressive of degradation, for death is not annihilation-must be the penalty if 
The turns from the source of life. The power of unbounded progress - which is the faculty of man under all circumstances-when directed to evil, that is, towards the creature rather than the Creator, would seem to infuse his being by a kind of burial into materiality, until at last he loses the mastery over subordinate creation, which was his birthright, and becomes subject where he ought to be supreme. If life indeed increases in perfection in proportion as man becomes congenerous with the Deity, so death must be deeper and more devoid of life as he sinks in the contrary direction.

To compare the present nature of humanity with the state from which it has fallen and to which it may rise, and to consider the cause which determined and perpetuates its ruin, is to throw much light upon the contradictions which exist in the vitality of man, and to explain why in the present state life is associated with want and disease and death, power with helplessness, and error with wisdom.

In the lower creation are signs of the presence of a vital principle similar to that which is found in man, but that is absent which is characteristic of humanity. The brute, indeed, is without freedom of will and immortality; it is an element in the general system of nature, but not integral and independent. "The spirit of the beast returns to the earth, but the 
soul of man unto God, who gave it." The one is a subject; the other is a potentate to whom was once entrusted-and who still continues to exercise in some degree - the administration of law. The one is ephemeral and transient: the other exists for ever.

It is difficult to deny to the higher brutes the phenomena of reason and understanding, nor in one sense is there any necessity to do so. There is no difficulty, indeed, in supposing the omnipresent spirit of Deity to be revealed in this manner, independently of any act of volition in the creature itself. There is no more difficulty, indeed, in supposing a revelation of the Deity in phenomena of reason or understanding, than in power and life,-for all are reflections of attributes which are inseparable: but it is an error to suppose that the brute has true volition; for all those signs of progress which are characteristic of the will are absent, and, moreover, the quasi-mental acts are unobscured by error, and directed to good and not to evil. The brute, indeed, is that irresponsible machine into which the fatalists degrade themselves.

The other instinctive impulses of the lower animals are to be accounted for in the same way, for they are constant and ever tending to the good of the creature. In the brute, indeed, there is no fallen and changeful principle, as in man, to thwart the beneficent purposes of the lawgiver and to mask the law.

The vitality of the lower ranks of created forms 
differs also from that of man in the absence of true disease and death. It is necessary, indeed, to regard the entire terrestrial system, excluding man, as an undivided whole, in which there is continual change, but no true separation. The old form suffers annitilation in the birth of the new, but not death, and in every change the life of the earth continues the same as a whole. Man, on the contrary, is independent and free to act, and so long as he is "lapsed in time and passion," in him there is true death - a death which, without approaching the nearer to annihilation, may go on for ever in progressively decreasing life.

In the lower forms of nature, therefore, we may suppose phenomena of vitality, analogons in their abstract essence to those which are found in man, lower in degree, but altogether uninfluenced by any potential principle of freedom, such as the will,-and we may infer that these phenomena are the natural effects of the presence of Deity in creation. If man did not exert a baneful influence upon the things around him, it is possible to suppose that disease - which in this case is incipient annihilation, and not preliminary death_-would be banished, and that the whole realm of inferior nature would be a universal display of happiness. To escape from the delusions of a fallen nature, indeed, is to attain to a point of view from whence we may reconcile many contradictions in 
the vital acts of man and the inferior creatures, and it may be seen that the difference of the former is not in the possession of another principle of life, but in the will. The essence of life is the same in all, and this when resolved into its highest expression, is the spirit of Deity.

2. The history of life shows an intimate and inseparable connexion between the force distinctive of unorganized substances and that of vitality, and it would appear that the two are correlated and interdependent.

Life is dormant in the seed during the frosts of winter, and the bare and desolate woods of our country, when coated with hoar-frost, seem half changed into stalactites; but in the perennial summer of tropical climes, vegetation teems in unfailing luxuriance. The dependence of life upon outward influences is evident also in the contrast presented by the scanty and threadbare carpet which clothes the shores of the icy sea, and the primeval and impenetrable forests which shadow the sultry channels of the Amazon and Cassequiaire-where, according to Humboldt, "all vegetation has a tendency to become ligneous."

The egg receives from without the influence which awakens and fosters the imprisoned animal. The vivacity of the squirrel is subdued in winter into the 
most deathlike torpidity. The bat, which in the summer evening rivals the bird in energy and activity, is benumbed and motionless in the dreary nights of winter. The swallow wings its way after the sun: and the shoals of fish that pass southward in the autumn, afford sufficient proof that these creatures cannot resist the cold of the arctic winter. And man himself is not free from the influence of the world without, and he is stunted, and passionless, and stolid, in regions most inimical to life, where cold reigns in unabated terrors.

On the other hand, the vital force of the organic world re-acts in the induction of the force associated with unorganized substances. The degree of heat is commensurate with vitality, as is evident if we compare the plant with the reptile, and these with the mammal. The spark of the glow-worm beams most brilliantly during the excitement of its amours, and wanes when these are ended. The terrors of the torpedo disappear when the animal is exhausted by fatigue, or upon the point of death.

This mutual dependence of the two forces of organic structures, would seem to indicate the existence of some common bond of connexion. And this inference, moreover, is not less probable, when we consider the union of the two realms of nature; for if there is no line of demarcation between organic structures and inorganic substances in regard to form, it is to be 
inferred that there will be the same absence of separation in force. From the community of form, indeed, it may be supposed that the principle of vitality in one or other manifestation is not confined to the things of life, just as on the other hand it is evident that the force which is especially distinctive of inorganic substances is not confined to these bodies. Hence an intimate connexion between the two forms of force may be inferred from other reasons than the passages in the history of life which have just been recited.

The vital influence (when viewed as a reflection of the Divine essence) may be associated with sensible bodies; but these are not necessary to its existence. The force, of which light and heat are expressions, on the other hand, are inseparably connected with materiality, and it is equally impossible to conceive matter without the force, or force without the matter. The one influence, therefore, may be said to resolve itself into spirit, and the other into matter, and the final question of unity of force becomes the oft-perplexed problem of the relation of matter to spirit.

What, then, it may be asked, is this relation? The answer is not difficult; and on the examination of the question, it is found that the idea of absulute distinction between matter and spirit is connected with the present state of man, and that it is an aberrant off- 
spring of the senses, equivalent to the errors of judgment of which we have already spoken. It may be seen that the eye is dim and darkened, and the image broken and deformed, because the vision is imperfect. It may be seen that the ear fancies discordant pauses in the symphony of Nature, because its perfect sense of melody is lost. It may be seen that the touch clothes objects with impenetrable boundaries, because it is palsied and crushed with the load of its own feebleness.

When compared with the higher standard of humanity of which we have spoken, the conclusion must be, that man is at present in a state of death-if, at least, this state is allowed to signify degradation, and not annihilation; and if so, then it may be shown that the impressions of things will be distinct and separate so long as we continue as we are.

That man is at present dead, may be readily seen. The commandment threatened death on the day of disobedience, and there is no reason to believe the sentence was commuted or deferred. At the moment of his sin, Adam suffered degradation-for the sense of nakedness evidencess subjection to the body; and the enmity of the serpent, together with the unwillingness of the earth, show that he had become too feeble to exercise that dominion over inferior creation which had been entrusted to him.

The actual condition of man may also be inter- 
preted by reference to the mystery which effects his restoration, and from this we may comprehend the nature of our life. Now it can scarcely be supposed that the death of our Saviour is confined exclusively to the final pang upon the cross; for such is the immeasurable descent from the Godhead, that the birth, the sorrow, the passion, the crucifixion, are but slightly differing degrees of a state, the whole of which is continual death. And if so, then it seems natural to suppose that the death of man is not confined to the final act of dissolution, but that it is a term applicable to the whole of his existence, before he wakes up to a fuller consciousness of internal being.

It must be observed, also, that the restoration of man is spoken of as resurrection, and the most unhappy fate as a continuance of the state in which we are, or in a still lower degradation, or second death. The question throughout is one of degree and not of kind; and if it be admitted that death is degradation, and not annihilation, - if it be admitted, also, that man is fallen, then it must be granted that in a greater or less degree he is at present dead.

Now death, in its abstract sense, may be said to be separation, primarily of the creature from the Creator, and secondarily in and among the creatures themselves. It is essentially a turning away to the part, and a forgetting of the divine principle of unity, which ensouls the whole: and detachment and separation must 
therefore be directly proportionate to the degree of death.

And that this is the case may be argued from the opposite proposition, in which it may be stated that union is in proportion to the degree of life. If we take the highest possible degree of life, as manifested in Christ, we may see that this is the case; and we may understand that there is no absolute distinction between the material and sensible humanity and the supersensuous principle. On the mountain, indeed, the external form became transfigured into life and power; and after the resurrection the same body became more completely changed, for while it received food and afforded satisfaction to the eye, the ear, and the touch, yet at the same time it was capable, as it were, of absorption into spirit, so that it could appear among the disciples when the door was shut, or vanish out of sight, as on the ascension from the Mount of Olives.

And if there be in man the higher nature of which we have spoken, it may be supposed that the human body, when completely emancipated from the fall, will assume the properties which appertained to the divine body. By the evil exercise of his will, man is at present in bondage to created forms, but he is capable of deliverance, and if so, then there must be a point where the affinity for his Creator gains the preponderance over the affinity to any created thing. To allow free-will to man and the capacity of 
unrestrained communion with Deity, is indeed to admit not only an emancipation from, but a dominion over, created things, - and to man, purified and restored, it is possible to suppose a real supremacy over the earth and the terrestrial part of his own nature. At the resurrection of the just, indeed, we are expressly told that the body shall be like unto Christ's glorious body. But alas! such beings do not linger visibly and sensibly in the wilderness of forms in which we wander, but they escape from the shadow of death which is upon the present world, and pass away as Christ has passed. It may be inferred, therefore, that the true nature of the body of man-always excepting that infinite and impassable distance which separates the uncreate Godhead from the creature-is revealed in our Saviour after his resurrection. In our Saviour, this nature is not miraculous, for it is impossible to conceive the Creator in bondage to any form which he has originated; and in man it is not miraculous if he exercises the high communion of which he is capable.

It may be inferred, therefore, that in man the idea of absolute distinction between body and spirit will vanish away when the standard of humanity is raised sufficiently high. Spirit must be regarded as perfectly real, and body as equally so, but still the two as connected and inseparate. Spirit, indeed, must be deemed susceptible of embodiment, and body of spiritualization. 
And if there be this unity of body and spirit in man, it may be argued that there is a similar unity in all forms and forces, whatever may be their character. In the entire realm of nature, a common archetype may be traced in form, and there is evidence also, that the force which actuates man is present also in the lower creation, if we except the human will. It is a necessary induction, therefore, that everywhere there shall be the same essential relation between form and spirit, and thus we attain to a focus in which all differences cease. Matter cannot be regarded as dead and inert, and separate from force, and by spiritualizing matter, we spiritualize also the force which is supposed distinctive of unorganized substances, and matter and force blend in a common term of unity.

I am unhappy if I give the readers of these pages any wrong impression of my opinion in these matters. Far be it from me to wish to degrade any sacred and sublime mystery into a mere philosophical abstraction, and though I would hold forth as a truth essential to the interpretation of the phenomena of vitality, the fallen position of man, yet I would never forget that the Godhead of Christ is absolute and infinite, and that to this our own being, though congenerous in essence, can never hold a higher relation than that of finite to infinite, or of created to Creator.

Man, I would contend, is so much nobler than he 
seems, that he can understand no one of his own acts if he assumes his own present state as the standard of judgment: but, on the contrary, if he will rouse in himself his higher being, and judge by the light which then breaks upon him, many contending mysteries will meet with their solution.

Take man in his perfect state, and he exercises a true vice-regal government over his own body and the rest of creation, and wields a divinely delegated power, so long as he continues faithful in his allegiance. In him there will be no death, or impotence, or ignorance, for by faith he receives into himself, according to his wants and wishes, the Deity, who is life, and power, and wisdom.

Let man forget his allegiance, and his high faculties crumble into ruin. Man, however, is boundless for evil as for good: and as he may progress infinitely into a more and more perfect assimilation with his Maker, and participate without limitation in the essence of Deity, so also he has an infinite capacity to sink into some created thing or into himself, becoming more and more enthralled by idolatry and selfishness. As he turns away to created things he will be filled with errors, and these will be manifested in every act of vitality, -in aberrations of reason, and understanding, and instinct,-in helplessness and uncertainty,-or in diseases and death. These errors are not mysteries, if we look at them from 
the higher position, but they are the natural consequences of the evil direction of the will. As in nature, indeed, there is in form and force a prevailing unity, which is the sensible reflection of the omnipresent Deity, so it must be evident that we may obtain no perfect life, or power, or wisdom, in any detached thing, for it is in the connexion of this with the whole, and the whole with the Infinite, that we obtain that which is hidden.

Remove, again, the free will of man, and there is no boundary between him and other living things. The mental and bodily acts in him as in them, under these circumstances, would be the unobstructed effects of the operation of the Omnipresent Spirit, and all must tend to good. According to the dignity or subordinance of the creature there would be differences in these acts, but this would be only in degree. $\mathrm{Ab}$ stract, indeed, the will from man, or suspend the operation of its fallen tendencies, and the instinct of the brute ceases to be a perplexed and tormenting question, for then the acts of the whole creation, whether mental or bodily, will be the undisturbed and consequently beneficial workings of that Divinity in which all move, and live, and have their being.

The idea of absolute difference is also the consequence of man's degraded position, and in the higher standard, in which the divinity of human nature preponderates over the bodily part, then unity is per- 
ceived where the difference seems greatest, even in matter and spirit. It is here where is found the final proof of unity in the several varieties of force, for the agents associated with unorganized substances must dissolve away with the matter itself into a common term with the principle of life. It is here also where is found not only the proof of unity in all varieties of force, but also in force and form; for if matter can disappear in spirit, and spirit become embodied, it follows that force may become form, and form be transfigured in power.

Nature, therefore, harmonizes with revelation, and the former cannot be understood in the fullest acceptation, except it be interpreted by the latter.

THE END. 